\title{
17 University
}

Chattopadhyay, K., Craig, G. A., Heras Ojea, M. J., Pait, M., Kundu, A., Lee, J., Murrie, M., Frontera, A., and Ray, D. (2017) Dangling and hydrolyzed ligand arms in [Mn3] and [Mn6] coordination assemblies: synthesis, characterization, and functional activity. Inorganic Chemistry, 56(5), pp. 2639-2652.

There may be differences between this version and the published version. You are advised to consult the publisher's version if you wish to cite from it.

http://eprints.gla.ac.uk/137697/

Deposited on: 21 March 2017

Enlighten - Research publications by members of the University of Glasgow http://eprints.gla.ac.uk 


\section{Dangling and Hydrolyzed Ligand Arms in [Mn 3$]$ and [Mn $]$ Coordination Assemblies: Synthesis, Characterization and Functional Activity}

Krishna Chattopadhyay, ${ }^{a}$ Gavin A. Craig, ${ }^{b}$ María José Heras Ojea, ${ }^{b}$ Moumita Pait, ${ }^{\text {a,c }}$ Animesh

Kundu, ${ }^{\text {a }}$ Junseong Lee,${ }^{c}$ Mark Murrie, ${ }^{b}$ Antonio Frontera ${ }^{d}$ and Debashis Ray ${ }^{a *}$

${ }^{a}$ Department of Chemistry, Indian Institute of Technology(IIT), Kharagpur, INDIA

${ }^{b}$ School of Chemistry, University of Glasgow, Glasgow G12 8QQ,UK

${ }^{c}$ Chonnam National University, Gwangju 61186, South Korea

${ }^{d}$ Departament de Química, Universitat de les Illes Balears, Crta de Valldemossa km 7.5, 07122

Palma de Mallorca (Baleares), SPAIN 


\begin{abstract}
Two flexible, branched and sterically constrained di- and tripodal side arms around a phenol backbone have been utilized in ligands $\mathrm{H}_{3} \mathrm{~L} 1$ and $\mathrm{H}_{5} \mathrm{~L} 2$ to isolate $\left\{\mathrm{Mn}_{6}\right\}$ and $\left\{\mathrm{Mn}_{3}\right\}$ coordination aggregates. 2,6-bis $\left\{(1\right.$-hydroxy-2-methylpropan-2-ylimino)methyl $\}$-4-methylphenol $\left(\mathrm{H}_{3} \mathrm{~L} 1\right)$ gave trinuclear complex $\left[\mathrm{Mn}_{3}\left(\mu-\mathrm{H}_{2} \mathrm{L1}\right)_{2}\left(\mu_{1,3}-\mathrm{O}_{2} \mathrm{CCH}_{3}\right)_{4}\left(\mathrm{CH}_{3} \mathrm{OH}\right)_{2}\right]\left(\mathrm{ClO}_{4}\right)_{2} \cdot 4 \mathrm{CH}_{3} \mathrm{OH}(\mathbf{1})$, whereas 2,6bis[\{1-hydroxy-2-(hydroxymethyl)butan-2-ylimino $\}$ methyl]-4-methylphenol $\left(\mathrm{H}_{5} \mathrm{~L} 2\right)$ provided hexanuclear complex $\left[\mathrm{Mn}_{6}\left(\mu_{4}-\mathrm{H}_{2} \mathrm{~L} 2\right)_{2}(\mu-\mathrm{HL} 3)_{2}\left(\mu_{3}-\mathrm{OH}\right)_{2}\left(\mu_{1,3}-\mathrm{O}_{2} \mathrm{CC}_{2} \mathrm{H}_{5}\right)_{4}\right]\left(\mathrm{ClO}_{4}\right)_{2} \cdot 2 \mathrm{H}_{2} \mathrm{O}$ (2). Binding of acetates and coordination of $\left\{\mathrm{H}_{2} \mathrm{~L} 1\right\}^{-}$provided a linear $\mathrm{Mn}^{\mathrm{III}} \mathrm{Mn}^{\mathrm{II}} \mathrm{Mn}^{\mathrm{III}}$ arrangement in 1. A $\mathrm{Mn}_{6}^{\mathrm{III}}$ fused diadamantane type assembly was obtained in $\mathbf{2}$ from propionate bridges, coordination of $\left\{\mathrm{H}_{2} \mathrm{~L} 2\right\}^{3-}$ and in situ generated $\{\mathrm{HL} 3\}^{2-}$. The magnetic characterization of 1 and 2 revealed the properties dominated by intramolecular antiferromagnetic exchange interactions and this was confirmed using DFT calculations. Complex 1 exhibited field-induced slow magnetic relaxation at $2 \mathrm{~K}$ due to the axial anisotropy of $\mathrm{Mn}^{\mathrm{III}}$ centres. Both the complexes show effective solvent dependent catechol oxidation towards $3,5-\mathrm{DTBCH}_{2}$ in air. The catechol oxidation abilities are comparable from two complexes of different nuclearity and structure.
\end{abstract}

Keywords: Coordination assembly; 2-amino-2-ethyl-propane-1,3-diol; 2-amino-2methylpropan-1-ol; Tripodal; Imine hydrolysis 


\section{Introduction}

In recent years coordination aggregates of manganese ions have received attention from synthetic point of view due to the involvement of several manganese ions in multinuclear metallocofactors ${ }^{1}$ and in the oxygen evolving centre (OEC) of photosystem II in green plants and cyanobacteria. $^{2-5}$ OEC contains a unique manganese-calcium-oxo cluster having a separated manganese centre. Studies on model compounds provide information during the stepwise growth of trinuclear and higher-order manganese complexes. These complexes can register large ground state spin $(S)$ values from ferromagnetic exchange interactions and/or spin frustration effects.

Over the years we are interested to develop methodologies for multinuclear manganese complexes of unique structures and spanning range of oxidation states. Discovery of new structural motifs were important because of their similarity in structural mimics, magnetic properties, and as oxidation catalysts. ${ }^{6-8}$ Synthesis of such $\mathrm{Mn}-\mathrm{O}$ clusters often uses trinuclear manganese-carboxylate $\left[\mathrm{Mn}_{3} \mathrm{O}\left(\mathrm{O}_{2} \mathrm{CMe}\right)_{6}(\mathrm{py})_{3}\right] \mathrm{ClO}_{4}$ as most promising starting material in presence of variety of in-situ generated and/or externally added coordinating groups. ${ }^{9}$ Reactions providing higher-nuclearity products of varying oxidation-state combinations and unusual structural motifs, starting from simple metal salts are of interest in rationalizing the stepwise growth. ${ }^{10}$ A renewed interest in manganese complexes of different nuclearity, in $\mathrm{N}$ and $\mathrm{O}$ donor environment, is evidenced from newer reports of synthesis and reactions. ${ }^{11-13}$ For example, a rational pathway can be proposed for the assembly of $\left[\mathrm{Mn}_{3}\right]$ and $\left[\mathrm{Mn}_{6}\right]$ coordination clusters showing aggregation of unknown type. In this regard the choice of new ligand system is important, which plays role in dictating the final outcome. Alcohol-arm bearing ligand systems while coordinating to a particular metal ion centre can show inclination to bridge nearby metal ions through the alkoxido groups. The ancillary ligands like carboxylato and hydroxido groups are versatile for extending the bridging network through coordination from vacant sites around different manganese ions.

In recent years we and others are working on simple phenol-based Schiff bases to assemble multiple metal ions in a single molecular entity. ${ }^{14-16}$ Use of the multiple alcohol-arm bearing ligand platforms might permit hydroxido/oxido core formation from water following coordination of manganese ions, which in turn could afford products of high nuclearity. Hydroxido/oxido entangled manganese-carboxylates are known to exhibit coordination 
aggregates having new structures and varying oxidation-state combinations involving $\mathrm{Mn}^{\mathrm{II}}, \mathrm{Mn}^{\mathrm{III}}$ and $\mathrm{Mn}^{\mathrm{IV}}$. Such aggregates having several metal ion centres in close proximity have shown renewed interests in the field of molecule-based magnets having large ground state spins. ${ }^{17-19}$ Incorporation of $\mathrm{Mn}^{\mathrm{III}}$ into the aggregates can induce a large magnetic anisotropy for single molecule magnet (SMM) behaviour. ${ }^{20}$ Naturally occurring catechol oxidase is the classic example for type 3 copper proteins that is responsible for the catalytic oxidation of a range of $o$ diphenol (catechol) to $o$-quinone. Laboratory prepared complexes of $\mathrm{Mn}(\mathrm{II} / \mathrm{III} / \mathrm{IV}), \mathrm{Ni}$ (II) and $\mathrm{Co}(\mathrm{II} / \mathrm{III})$ have been shown to promote such activity, mimicking the above mentioned biological counterpart, to a greater or smaller extent. ${ }^{21-23}$

Herein we have explored the binding potential of $\mathrm{H}_{3} \mathrm{~L} 1$ and $\mathrm{H}_{5} \mathrm{~L} 2$ (Scheme 1) to isolate and study new multinuclear manganese carboxylate and hydroxide aggregates. Simple manganese(II) salts

\section{Scheme 1. Two types of ligands having different alcohol-arms}
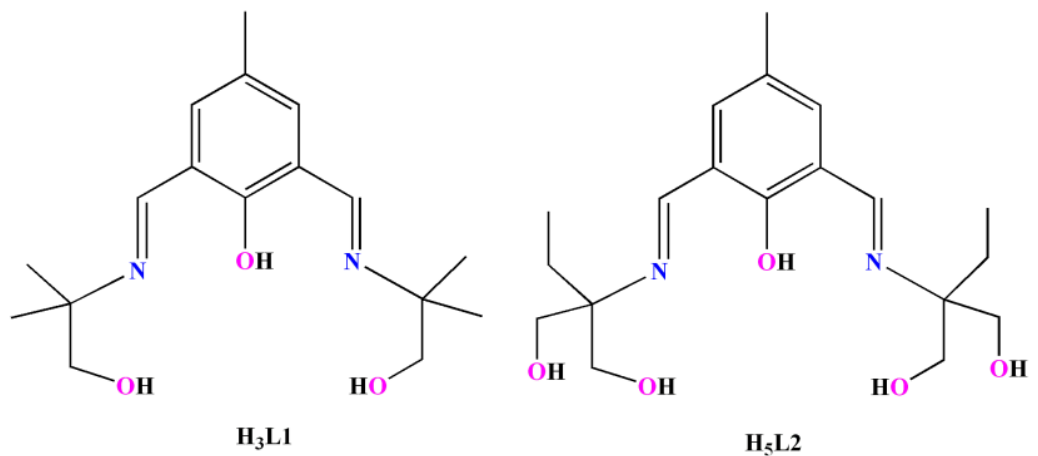

have been used in presence of different carboxylate ions. Recently we and others have utilized $\mathrm{H}_{3} \mathrm{~L} 1$ for the synthesis of $\left[\mathrm{Ni}_{4}\right],\left[\mathrm{Ni}_{6}\right]^{24}$ and $\left[\mathrm{Cu}_{6}\right]^{25}$ complexes. The coordination chemistry of $\mathrm{H}_{5} \mathrm{~L} 2$ is unknown in the literature. This paper reports new $\left[\mathrm{Mn}_{3}\right]$ and $\left[\mathrm{Mn}_{6}\right]$ complexes $\left[\mathrm{Mn}_{3}(\mu-\right.$ $\left.\left.\mathrm{H}_{2} \mathrm{~L} 1\right)_{2}\left(\mu_{1,3}-\mathrm{O}_{2} \mathrm{CCH}_{3}\right)_{4}\left(\mathrm{CH}_{3} \mathrm{OH}\right)_{2}\right]\left(\mathrm{ClO}_{4}\right)_{2} \cdot 4\left(\mathrm{CH}_{3} \mathrm{OH}\right)$ and $\left[\mathrm{Mn}_{6}\left(\mu_{4}-\mathrm{H}_{2} \mathrm{~L} 2\right)_{2}(\mu-\right.$ $\left.\mathrm{HL} 3)_{2}\left(\mu_{3}-\mathrm{OH}\right)_{2}\left(\mu_{1,3}-\mathrm{O}_{2} \mathrm{CC}_{2} \mathrm{H}_{5}\right)_{4}\right]\left(\mathrm{ClO}_{4}\right)_{2} \cdot 2 \mathrm{H}_{2} \mathrm{O}(2)$, respectively. The former has been assembled via the connections of two ligand bound mononuclear $\left\{\mathrm{Mn}\left(\mathrm{H}_{2} \mathrm{~L} 1\right)\right\}^{2+}$ fragments by ancillary carboxylate ions and terminal $\mathrm{MeOH}$ ligands. In the latter cluster the ligand bound $\left\{\mathrm{Mn}\left(\mathrm{H}_{4} \mathrm{~L} 2\right)\right\}^{2+}$ units and $\mu_{3}$-hydroxido- $\mu$-carboxylato bridged trinuclear motifs $\left[\operatorname{Mn}_{3}(\mu-\right.$ $\left.\mathrm{OH})\left(\mu_{1,3}-\mathrm{O}_{2} \mathrm{CC}_{2} \mathrm{H}_{5}\right)\right]$ condense together to result in the isolated cluster. Initial condensation of two $\left[\mathrm{Mn}_{3}(\mu-\mathrm{OH})\left(\mu-\mathrm{O}_{2} \mathrm{CC}_{2} \mathrm{H}_{5}\right)\right]$ units provided a planar $\left\{\mathrm{Mn}_{4}\left(\mu_{3}-\mathrm{OH}\right)_{2}\left(\mu-\mathrm{O}_{2} \mathrm{CC}_{2} \mathrm{H}_{5}\right)_{4}\right\}$ unit as the backbone on which the fused diadamantane-like $\left[\mathrm{Mn}_{6}\right]$ structural motif resulted. Their 
magnetic exchange interactions involving different metal centers have been examined in the solid state and catalytic activities have also been scrutinized in the solution phase.

\section{Experimental section}

\section{Materials}

The solvents and chemicals used were reagent-grade materials and were purchased from commercial sources like S. D. Fine Chem. Ltd. (India), SRL, E. Merck (India), Sigma Aldrich (USA), and Alfa Aesar. Without further purification all the chemicals were directly used as received. The sources of the chemicals are as follows: Sodium acetate from S. D. Fine Chem (India), propionic acid from E. Merck (India), 2-amino-2-ethylpropane-1,3-diol and 2-amino-2methylpropan-1-ol from Alfa aesar. 2,6-diformyl-4-methylphenol was synthesized in gram-scale following a modified literature procedure giving improved yield. ${ }^{26} \mathrm{Mn}\left(\mathrm{ClO}_{4}\right)_{2} \cdot 6 \mathrm{H}_{2} \mathrm{O}$ was prepared by treating an aqueous perchloric acid (1:1) solution with commercial $\mathrm{MnCO}_{3}$. The sodium propionate was prepared by neutralizing propionic acid $(0.15 \mathrm{~g}, 2.0 \mathrm{mmol})$ with an equivalent amount of solid $\mathrm{NaOH}(0.08 \mathrm{~g}, 2.0 \mathrm{mmol})$ followed by concentration on a water bath. All other chemical compounds and solvents were reagent-grade materials and were used as received without further purification.

Caution! Metal complexes of organic ligands with perchlorate counter ions are potentially explosive in nature in dry state. Therefore the material should be prepared in very small amount, and it should be handled with extreme care.

\section{Synthesis}

H3L1 (2,6-bis((1-hydroxy-2-methylpropan-2-ylimino)methyl)-4-methylphenol). To a methanol solution (15 mL) containing 2,6-diformyl-4-methylphenol (0.80 g, $5.0 \mathrm{mmol})$, 2amino-2-methylpropan-1-ol $(0.75 \mathrm{~g}, 10.0 \mathrm{mmol})$ was mixed by constant stirring. Then the reaction mixture was stirred for about an hour. Several attempts made to separate the solid ligand were unsuccessful. The $\mathrm{MeOH}$ solvent is evaporated by using rotatory evaporator to obtain $\mathrm{H}_{3} \mathrm{~L} 1$ as an oily mass, which was characterised, by FT-IR, ${ }^{1} \mathrm{H}-\mathrm{NMR},{ }^{13} \mathrm{C}$ NMR.

FTIR (cm ${ }^{-1}, \mathrm{KBr}$ pellet): 3394(vs), 2974(w), 1635(s), 1061(m), 682(w). ${ }^{1} \mathrm{H}$ NMR (600 MHz, $\left.\mathrm{CDCl}_{3}, \delta \mathrm{ppm}\right): 8.35(2 \mathrm{H},-\mathrm{N}=\mathrm{CH}), 7.24(2 \mathrm{H}$, Aromatic H$), 3.49\left(4 \mathrm{H},-\mathrm{CH}_{2}\right), 2.12\left(3 \mathrm{H},-\mathrm{CH}_{3}\right.$ attached with benzene ring), $1.17\left(12 \mathrm{H},-\mathrm{CH}_{3}\right) .{ }^{13} \mathrm{C} \mathrm{NMR}\left(150 \mathrm{MHz}, \mathrm{CDCl}_{3}, \delta \mathrm{ppm}\right): 162.03$ 
(imine C), 135.22-124.24 (Aromatic C), 71.26 (methylene C attached with Oxygen), 60.73 (tertiary $\mathrm{C}$ attached to imine $\mathrm{N}$ ), (26.33-20.04 (methyl C).

\section{H5L2 (2,6-bis((1-hydroxy-2-(hydroxymethyl)butan-2-ylimino)methyl)-4-methylphenol).}

$\mathrm{H}_{5} \mathrm{~L} 2$ was synthesized from Schiff base condensation reaction of 2,6-diformyl-4-methylphenol (1.0 g, $6.1 \mathrm{mmol})$ and 2-amino-2-ethyl-propan-1,3-diol (1.3 g, $12.2 \mathrm{mmol})$ in methanol solvent under stirring condition for $1 \mathrm{~h}$ under aerobic condition followed by reflux for $2 \mathrm{~h}$ (Scheme S1 in the Supporting Information, SI). The solvent was removed completely by evaporation in air and an orange oily substance was obtained. The orange color oily substance, $\mathrm{H}_{5} \mathrm{~L} 2$, was characterised by FTIR and NMR spectroscopy. Major ${ }^{1} \mathrm{H}$ NMR peaks confirm the ligand formation. The ligand was used directly for complexation reactions without further purification.

FTIR ( $\mathrm{cm}^{-1}, \mathrm{KBr}$ pellet): 3421(vs), 1636(s), 1054(w), 619(w). ${ }^{1} \mathrm{H}$ NMR (600 MHz, $\mathrm{CDCl}_{3}, \mathrm{ppm}$ ): $8.345(2 \mathrm{H},-\mathrm{N}=\mathrm{CH}), 7.34-7.28(2 \mathrm{H}$, Aromatic $\mathrm{H}), 3.35\left(8 \mathrm{H},-\mathrm{OCH}_{2}\right), 2.22\left(3 \mathrm{H},-\mathrm{CH}_{3}\right.$ substituent on phenyl ring) $1.61\left(4 \mathrm{H},-\mathrm{CH}_{2}\right), 0.86\left(6 \mathrm{H},-\mathrm{CH}_{3}\right) .{ }^{13} \mathrm{C} \mathrm{NMR}\left(150 \mathrm{MHz}, \mathrm{CDCl}_{3}\right.$, ppm): 165.41 (imine C), 161.61-125.25 (Aromatic C), 65.31 (methylene $\mathrm{C}$ attached with oxygen), 64.7 (terciary $\mathrm{C}$ attached to immine $\mathrm{N}$ ), 25.04 (methyl $\mathrm{C}$ attached with benzene ring), 20.40 (methelene C), 7.29 (methyl C)

$\left[\mathrm{Mn}_{3}\left(\boldsymbol{\mu}-\mathrm{H}_{2} \mathrm{L1}\right)_{2}\left(\boldsymbol{\mu}_{1,3}-\mathrm{O}_{2} \mathrm{CCH}_{3}\right)_{4}\left(\mathrm{CH}_{3} \mathrm{OH}\right)_{2}\right]\left(\mathrm{ClO}_{4}\right)_{2} \cdot 4 \mathrm{CH}_{3} \mathrm{OH}$ (1). To a $\mathrm{MeOH}$ solution (10 mL) of $\mathrm{H}_{3} \mathrm{~L} 1(1 \mathrm{mmol}, 0.31 \mathrm{~g})$ in a conical flask, $2 \mathrm{mmol}(0.72 \mathrm{~g}) \mathrm{Mn}\left(\mathrm{ClO}_{4}\right)_{2} \cdot 6 \mathrm{H}_{2} \mathrm{O}$ was added under constant starring. After $15 \mathrm{~min}$ of stirring, sodium acetate $(2 \mathrm{mmol}, 0.16 \mathrm{~g})$ was added to it. The solution became brown in color. The entire mixture was then refluxed for about an hour. After that, the solution was filtered and kept for slow evaporation. Brown crystalline solid was obtained on slow evaporation of the solvent. The compound was then recrystallized from $\mathrm{MeOH}-$ $\mathrm{MeCN}$ mixture (1:1) and nice brown crystals suitable for single crystal X-Ray diffraction were obtained after one week. Yield: $0.59 \mathrm{~g}, 63 \%$. Anal. calcd for $\mathrm{C}_{48} \mathrm{H}_{82} \mathrm{Cl}_{2} \mathrm{Mn}_{3} \mathrm{~N}_{4} \mathrm{O}_{28}$ (1398.86 g $\mathrm{mol}^{-1}$ ): C, 41.21; H, 5.91; N, 4.01. Found: C, 41.16; H, 5.85; N, 3.90\%. Selected FTIR bands $\left(\mathrm{KBr}, \quad \mathrm{cm}^{-1}\right.$ ): 3421(broad), 1658(strong), 1603(strong), 1549(strong), 1405(medium), 1090(medium). Molar conductance, $\Lambda_{\mathrm{M}}$ (Methanol solution, $\Omega^{-1} \mathrm{~cm}^{2} \mathrm{~mol}^{-1}$ ): 164.2. UV-Vis spectra $\left[\lambda_{\max }, \mathrm{nm}\left(\varepsilon, \mathrm{L} \mathrm{mol}^{-1} \mathrm{~cm}^{-1}\right)\right]$ (MeCN solvent): 586 (110), 399 (16200), 255 (54240).

$\left[\mathrm{Mn}_{6}\left(\mu_{4}-\mathrm{H}_{2} \mathrm{L2}\right)_{2}(\mu-\mathrm{HL} 3)_{2}\left(\mu_{3}-\mathrm{OH}\right)_{2}\left(\mu_{1,3}-\mathrm{O}_{2} \mathrm{CC}_{2} \mathrm{H}_{5}\right)_{4}\right]\left(\mathrm{ClO}_{4}\right)_{2} \cdot 2 \mathrm{H}_{2} \mathrm{O}$ (2). A MeOH solution (15 $\mathrm{mL})$ of $\mathrm{Mn}\left(\mathrm{ClO}_{4}\right)_{2} \cdot 6 \mathrm{H}_{2} \mathrm{O}(0.90 \mathrm{~g}, 2.5 \mathrm{mmol})$ was added drop wise during $10 \mathrm{~min}$ to a methanol 
$(10 \mathrm{~mL})$ solution of $\mathrm{H}_{5} \mathrm{~L} 2(0.37 \mathrm{~g}, 1.0 \mathrm{mmol})$ under constant stirring. The solution color was changed to wine red. After $15 \mathrm{~min}$ sodium propionate ( $2 \mathrm{mmol}, 0.20 \mathrm{~g}$ ) salts was added to the reaction mixture when solution color changed to dark brown. The reaction mixture was further stirred for $2 \mathrm{~h}$. After that the solution was filtered and slow evaporation of the solvent at ambient condition gave brown block type crystals suitable for X-ray diffraction after 12 days. Yield: 1.40 g, 65\%. Anal. calcd for $\mathrm{C}_{78} \mathrm{H}_{110} \mathrm{Cl}_{2} \mathrm{Mn}_{6} \mathrm{~N}_{6} \mathrm{O}_{38}\left(2140.26 \mathrm{~g} \mathrm{~mol}^{-1}\right)$ : C, 43.77; H, 5.18; N, 3.93. Found: C, 43.52; H, 5.13; N, 4.02. Selected FT-IR bands (KBr, cm $\left.{ }^{-1}\right)$ : 3404(broad), 2967(medium), 1645(s), 1620(strong), 1577(strong), 1547(strong), 1454(medium), 1140(medium), 1115(medium), 1078(strong), 621(medium). Molar conductance, $\Lambda_{\mathrm{M}}$ (Methanol solution, $\left.\Omega^{-1} \mathrm{~cm}^{2} \mathrm{~mol}^{-1}\right)$ : 182.4. UV-Vis spectra $\left[\lambda_{\max }, \mathrm{nm}\left(\varepsilon, \mathrm{L} \mathrm{mol}^{-1} \mathrm{~cm}^{-1}\right)\right](\mathrm{MeCN}$ solvent): 586 (170), 410 (27200), 264 (94557).

Physical Measurements. The purity of the complexes was examined by measuring the percentage of Carbon, Hydrogen, Nitrogen with a Perkin-Elmer model 240C elemental analyzer. A Shimadzu UV-vis-NIR spectrophotometer model UV 3100 was used for recording the solution state electronic absorption spectra of the compounds. A Perkin-Elmer FT-IR spectrometer model RX1 was used to obtain the FT-IR spectra on KBr pellets. The high resolution mass spectra (HRMS) of the compounds were recorded in electrospray ionization (ESI) mode using a Bruker esquire 3000 plus mass spectrometer. The electrical conductivity of the compounds were measured in methanol solvent by a Unitech type U131C digital conductivity meter with a solute concentration of about $10^{-3} \mathrm{M}$. The powder X-ray diffraction patterns of the powder compounds were recorded by using a Bruker AXS X-ray diffractometer $(40 \mathrm{kV}, 20 \mathrm{~mA})$ with $\mathrm{Cu} \mathrm{K} \alpha$ radiation $(\lambda=1.5418 \AA)$ with an angular range of $(2 \theta)$ of $5-50^{\circ}$. EPR spectra were recorded at $9.13 \mathrm{GHz}$ (X-band) in CW mode with a Bruker ELEXSYS 580 Xband EPR spectrometer equipped with a standard accessory for room temperature operation (298 $\mathrm{K})$.

Magnetic Measurements. Direct current (dc) and alternating current (ac) magnetic measurements were performed on polycrystalline samples of compounds $\mathbf{1}$ and $\mathbf{2}$ constrained in eicosane, using a Quantum Design SQUID magnetometer furnished with a $5 \mathrm{~T}$ magnet in the School of Chemistry at the University of Glasgow. The dc measurements were carried out in the temperature range $290-1.8 \mathrm{~K}$ under an applied field of 1000 Oe. Field-dependent magnetisation 
measurements were performed at 2, 4, and $6 \mathrm{~K}$, over the range $0-5 \mathrm{~T}$. Dynamic susceptibility measurements were carried out over the temperature range $2-10 \mathrm{~K}$, with a drive field of 3 Oe, and a frequency range of 1 to $1488 \mathrm{~Hz}$. Data were corrected for the diamagnetism of the compound through the approximation that $\chi_{\text {DIA }} \sim 0.5 \times M W \times 10^{-6} \mathrm{~cm}^{3} \mathrm{~mol}^{-1}(M W=$ molecular weight), and for the diamagnetic contributions of the sample holder and eicosane through measurements.

Method for Kinetic Study. The catecholase activity of the complexes were studied in $\mathrm{MeOH}$ and $\mathrm{MeCN}$ separately using 3,5-di-tert-butylcatechol (3,5-DTBCH 2$)$ as the model substrate. The oxidation of 3,5-DTBCH 2 to 3,5-DTBQ (3,5-di-tert-butylquinone) was followed on a Shimadzu UV 3100 UV-Vis-NIR spectrophotometer. The reactions were monitored at the quinone band maxima at $\sim 400 \mathrm{~nm}$. Kinetic experiments were performed in $\mathrm{MeOH}$ and $\mathrm{MeCN}$ medium and different reaction sets were examined using constant concentration $\left(\sim 1.0 \times 10^{-5} \mathrm{M}\right)$ of complexes and varying amount of 3,5- $\mathrm{DTBCH}_{2}$ (10 to 100 equivalents) and the spectral changes were monitored with time at band maxima of quinone. The initial rates for each catalyst-substrate combination were calculated from the slope of the absorbance vs. time plot. Kinetic analyses were executed following the Michaelis-Menten method and important kinetic parameters were derived from the Lineweaver-Burk plots.

Crystal Structure Determination. Suitable single crystals of $\mathbf{1}$ and $\mathbf{2}$ were chosen for X-ray diffraction and the data were collected on a Bruker SMART APEX-II CCD X-ray diffractometer which is furnished with a graphite-monochromated Mo-K $\alpha(\lambda=0.71073 \AA)$ radiation by the $\omega$ scan method at $293 \mathrm{~K}(100 \mathrm{~K}$, for $\mathbf{1})$ with a counting time of $4 \mathrm{~s}$ per frame. Data integration, reduction and Space group determination were performed using XPREP and SAINT software. ${ }^{27}$ The structures were solved using the direct method through the SHELXS- $97^{28}$ and refined by SHELXL-97 ${ }^{29}$ program package associated to WINGX system Version 1.80.05. ${ }^{30}$ The locations of the heaviest atoms (Mn) were determined easily, and the $\mathrm{O}, \mathrm{N}$, and $\mathrm{C}$ atoms were then fixed from the difference Fourier maps. Anisotropic refinement was performed for the non-hydrogen atoms. $\mathrm{H}$ atoms were incorporated in calculated positions and refined using fixed geometry and riding thermal parameters. All the crystallographic diagrams were generated using Diamond ${ }^{31}$ and POV-ray ${ }^{32}$ software. Information regarding the X-ray diffraction data collection and 
structure refinements of the compounds is provided in Table S1. CCDC 1517620 and 1517621 contain the supplementary crystallographic data of the two compounds.

Theoretical methods. The magnetic properties of the two compounds have been calculated employing density functional theory (DFT) in combination with the broken symmetry approach $^{33-35}$ with the help of GAUSSIAN 09 package. ${ }^{36}$ This study used B3LYP/6-31G* level of theory which is a good agreements between the size of the systems and the computational demands. The crystallographic coordinates where the positions of the hydrogens have been optimized, have been used for these calculations. Moreover, the theoretical models have been simplified using $\mathrm{H}$ atoms instead of methyl groups in the ligand.

For the linear trinuclear system $\mathrm{Mn}(\mathrm{III})-\mathrm{Mn}$ (II)-Mn(III) $\mathbf{1}$, we have a strictly symmetric system in which two of the terminal magnetic centers $\left(\mathrm{Mn} 1\right.$ and $\mathrm{Mn} 1^{*}$, see Figure 1 for labelling scheme) are related to a symmetry element that passes across the third one (Mn2). Therefore, we can conclude that $J_{12}=J_{21}=J$ with a consequent simplification of the calculations. ${ }^{37,38}$ Further, the interaction between $\mathrm{Mn} 1$ and $\mathrm{Mn} 1 *$ can be neglected taking into account the large separation of the two $\mathrm{Mn}$ (III) metal centers at two ends. Therefore, the magnetic coupling constant of compound 1 can be obtained using the energy of only two states. For the calculations of the hexanuclear complex 2 , we have evaluated each individual coupling constant ( $J_{1}$ to $J_{4}$ ) using the methodology proposed by Alvarez group ${ }^{39,40}$ in mutinuclear systems. This method consists of substituting paramagnetic atoms by diamagnetic ones to reduce the evaluation of coupling constants to calculations for magnetically dinuclear complexes. This strategy is very convenient and accurate to estimate each individual coupling constant.

\section{Results and Discussion}

Synthetic Concerns. $\mathrm{H}_{3} \mathrm{~L} 1$ and $\mathrm{H}_{5} \mathrm{~L} 2$ were examined for their ability to trap multiple metal ions in $\left[\mathrm{Mn}_{3}\right](\mathbf{1})$ and $\left[\mathrm{Mn}_{6}\right]$ (2) aggregates (Scheme 2). Reaction of $\mathrm{H}_{3} \mathrm{~L} 1$ with $\mathrm{Mn}\left(\mathrm{ClO}_{4}\right)_{2} \cdot 6 \mathrm{H}_{2} \mathrm{O}$ and $\mathrm{CH}_{3} \mathrm{CO}_{2} \mathrm{Na}$ in 1:2:2 molar ratio in $\mathrm{MeOH}$ and in absence of any added base in air resulted 1.

Oxygen of air was consumed for partial oxidation of terminal $\mathrm{Mn}^{\mathrm{II}}$ centres to $\mathrm{Mn}^{\mathrm{III}}$ in $\mathbf{1}$ (vide supra). The course of the reaction followed by the crystallization for $\mathbf{1}$ is summarized in eq 1 below. 
$2 \mathrm{H}_{3} \mathrm{Ll}+3 \mathrm{Mn}\left(\mathrm{ClO}_{4}\right)_{2} \cdot 6 \mathrm{H}_{2} \mathrm{O}+4 \mathrm{CH}_{3} \mathrm{CO}_{2} \mathrm{Na}+(1 / 2) \mathrm{O}_{2} \stackrel{\mathrm{MeOH}}{\longrightarrow}$ [Brown crystalline material] $\stackrel{\mathrm{MeOH}-\mathrm{MeCN}}{\longrightarrow}\left[\mathrm{Mn}_{2}^{\mathrm{III}} \mathrm{Mn}^{\mathrm{II}}\left(\mathrm{H}_{2} \mathrm{~L} 1\right)_{2}\left(\mu_{1,3}-\mathrm{O}_{2} \mathrm{CCH}_{3}\right)_{4}\left(\mathrm{CH}_{3} \mathrm{OH}\right)_{2}\right]\left(\mathrm{ClO}_{4}\right)_{2} \cdot 4 \mathrm{CH}_{3} \mathrm{OH}$

During the formation of $\mathbf{1}$ in solution, two deprotonated $\left\{\mathrm{H}_{2} \mathrm{~L} 1\right\}^{-}$gave two $\left\{\mathrm{Mn}^{\mathrm{III}}\left(\mathrm{H}_{2} \mathrm{~L} 1\right)\left(\mathrm{O}_{2} \mathrm{CCH}_{3}\right)\left(\mathrm{H}_{2} \mathrm{O}\right)_{2}\right\}^{+}$units for the trapping of in situ generated $\left\{\mathrm{Mn}^{\mathrm{II}}\left(\mathrm{O}_{2} \mathrm{CCH}_{3}\right)_{2}\right\}$ in the reaction medium. Thus, the molecular structure of $\mathbf{1}$ is composed of two ligand-bound terminal $\mathrm{Mn}^{\mathrm{III}}$ centres connected by a central ligand-free $\mathrm{Mn}^{\mathrm{III}}$ unit through the alkoxido bridges of ligand and oxygen connectors of carboxylate anions. (vide supra)

Interestingly reaction of $\mathrm{H}_{5} \mathrm{~L} 2$ with $\mathrm{Mn}\left(\mathrm{ClO}_{4}\right)_{2} \cdot 6 \mathrm{H}_{2} \mathrm{O}$ and $\mathrm{C}_{2} \mathrm{H}_{5} \mathrm{CO}_{2} \mathrm{Na}$ in lieu of $\mathrm{CH}_{3} \mathrm{CO}_{2} \mathrm{Na}$ as used in the previous case and in 1:2.5:2 molar ratio in $\mathrm{MeOH}$ resulted in 2 in 65\% yield. Direct reaction of the components in $\mathrm{MeOH}$ solution leads to brown powdered complex which on recrystallization from $\mathrm{MeOH}-\mathrm{MeCN}$ mixture (1:1) gave brown crystals. Several reactant stoichiometries were tried before the above-mentioned molar ratio was settled. The course of reaction for the formation of $\mathbf{2}$ is given below.

$$
\begin{aligned}
4 \mathrm{H}_{5} \mathrm{~L} 2+ & 6 \mathrm{Mn}\left(\mathrm{ClO}_{4}\right)_{2} \cdot 6 \mathrm{H}_{2} \mathrm{O}+10 \mathrm{C}_{2} \mathrm{H}_{5} \mathrm{CO}_{2} \mathrm{Na}+(3 / 2) \mathrm{O}_{2} \stackrel{\mathrm{MeOH}}{\longrightarrow} \\
& {\left[\mathrm{Mn}_{6}^{\mathrm{IIII}}\left(\mathrm{H}_{2} \mathrm{~L} 2\right)_{2}(\mathrm{HL} 3)_{2}\left(\mu_{3}-\mathrm{OH}\right)_{2}\left(\mu_{1,3}-\mathrm{O}_{2} \mathrm{CC}_{2} \mathrm{H}_{5}\right)_{4}\right]\left(\mathrm{ClO}_{4}\right)_{2} \cdot 2 \mathrm{H}_{2} \mathrm{O}+10 \mathrm{NaClO}_{4} } \\
& +6 \mathrm{C}_{2} \mathrm{H}_{5} \mathrm{CO}_{2} \mathrm{H}+35 \mathrm{H}_{2} \mathrm{O}
\end{aligned}
$$


Scheme 2. Synthetic routes to complexes 1 and 2

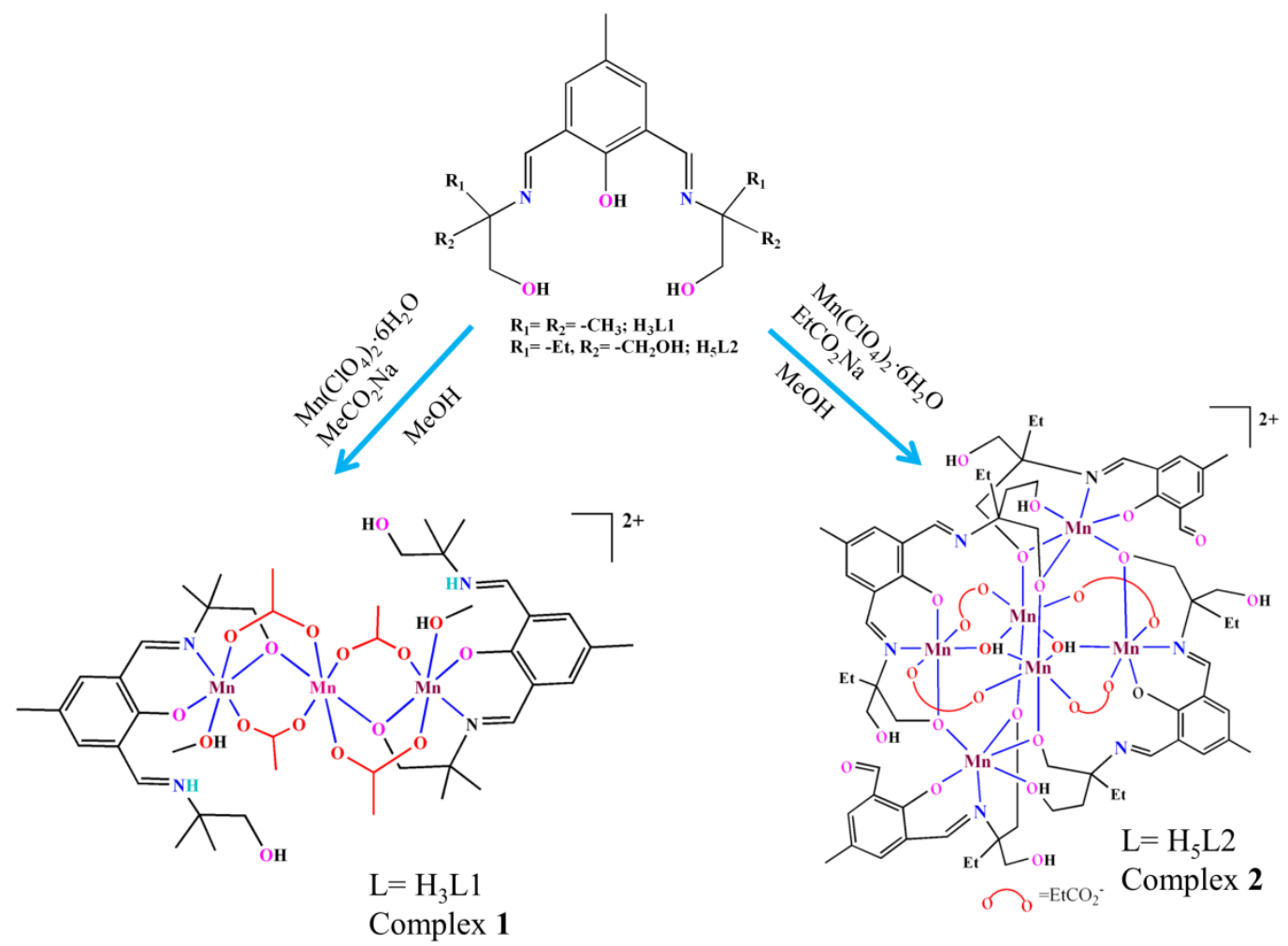

During the complexation reaction under aerobic conditions, the Mn(II) ions from the perchlorate salt undergo aerial oxidation leading to the entrapment of $\mathrm{Mn}(\mathrm{III})$ in the final product, 2 . Metal ion coordination induced partial hydrolysis generates hydrolysed ligand $\mathrm{H}_{3} \mathrm{~L} 3$ (Scheme 3) and gives stability to the final isolable species.

Scheme 3. Coordination induced partial hydrolysis of $\mathrm{H}_{5} \mathrm{~L} 2$ to $\mathrm{H}_{3} \mathrm{L3}$

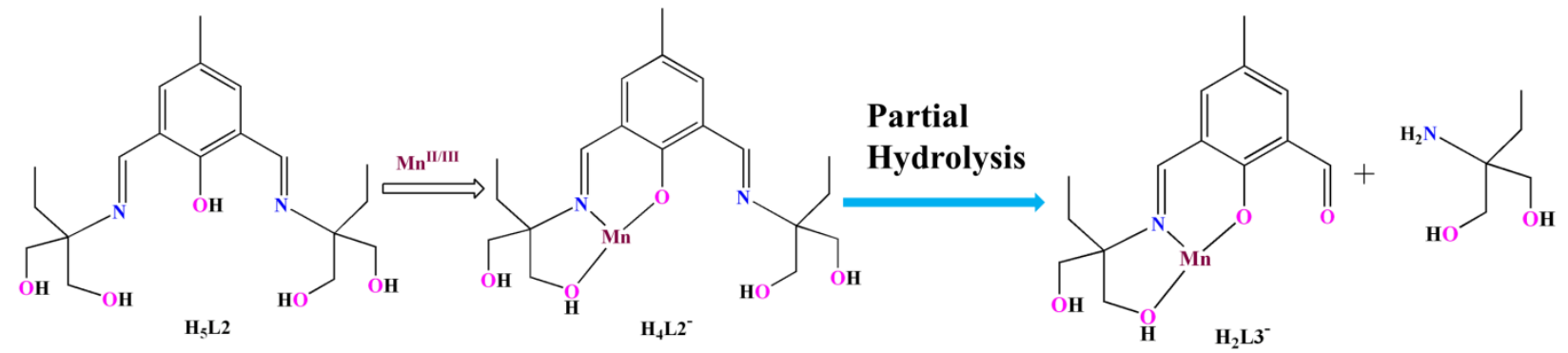

Hydrolysis of imine arms by solvent/bases to produce 2-aminoethanol in the reaction medium is well known. ${ }^{41}$ Steric crowding on the $\alpha$-carbon to the amine function further facilitates the removal of substituted 2-aminoethanol group following oxidation of $\mathrm{Mn}^{\mathrm{II}}$ centre to $\mathrm{Mn}^{\mathrm{III}}$ and 
coordination within ONO tridentate pocket of $\{\mathrm{HL} 3\}^{2-}$. The removed bis-hydroxymethyl amine, capable of bridging multiple metal ions in free form, was not suitable under these reaction conditions to show coordination or chelation. Both the complexes have been characterized by FTIR (Figure S1) and electronic spectral measurements (See supporting information). The phase purity of the complexes is confirmed by powder X-ray diffraction (PXRD) studies. The experimental PXRD patterns (Figure S2) are in good agreement with the simulated ones obtained from single crystal XRD data.

\section{Structural Description}

$\left[\mathrm{Mn}_{3}\left(\mu-\mathrm{H}_{2} \mathrm{L1}\right)_{2}\left(\mu_{1,3}-\mathrm{O}_{2} \mathrm{CCH}_{3}\right)_{4}\left(\mathrm{CH}_{3} \mathrm{OH}\right)_{2}\right]\left(\mathrm{ClO}_{4}\right)_{2} \cdot 4 \mathrm{CH}_{3} \mathrm{OH}(1)$. Compound 1 crystallizes in the triclinic crystal system and $P \overline{1}$ space group. The perspective view of the mixed valence trinuclear cationic unit is shown in Figure 1.

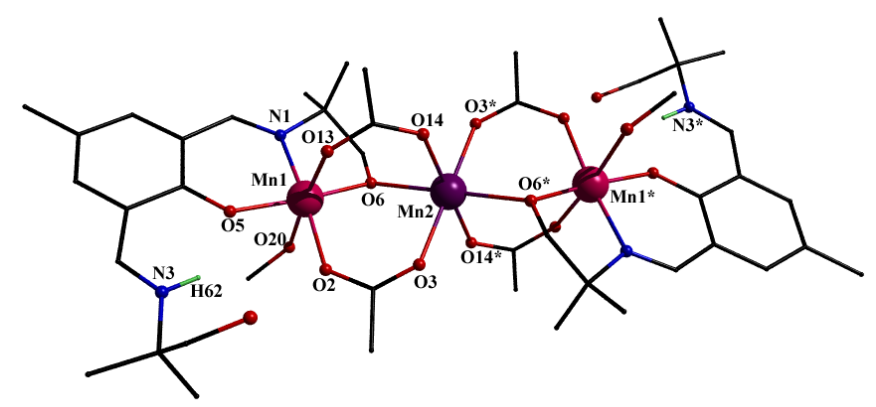

Figure 1. View of the complex unit in $\mathbf{1}$ with partial atom numbering scheme. Counter ions, solvent molecules in the lattice are omitted for clarity. H-atoms are shown only for the protonated imine group. Color code: $\mathrm{C}$ black, $\mathrm{N}$ blue, $\mathrm{O}$ red, $\mathrm{Mn}^{\mathrm{II}}$ purple, $\mathrm{Mn}^{\mathrm{III}}$ pink.

Complex 1 has a linear trinuclear structure with the central $\mathrm{Mn}^{\mathrm{II}}$ ion at the inversion centre. Each $\{\mathrm{HL} 1\}^{2-}$ anion derived from $\mathrm{H}_{3} \mathrm{~L} 1$ ligand, provides tridentate ONO meridional coordination to terminal $\mathrm{Mn}^{\mathrm{III}}$ ions $(\mathrm{Mn} 1$ and $\mathrm{Mn} 1 *)$. The deprotonated alkoxido ions of ligand arms from two ligands bridge the central $\mathrm{Mn}^{\mathrm{II}}$ ion $(\mathrm{Mn} 2)$. The second pockets of the ligands remain vacant and the imine $\mathrm{N}$ is protonated in zwitterionic form (Chart I).

Two ligand bound terminal $\left\{\mathrm{Mn}^{\mathrm{III}}(\mathrm{L} 1)\right\}^{2+}$ units are connected to the central $\mathrm{Mn}^{\mathrm{II}}$ ion by the alkoxido ligand ends (O6 and O6*) and two exogenous acetate groups (Figure S3). 


\section{Chart I. Coordination zwitterionic $\mathrm{H}_{3} \mathrm{~L} 1$}

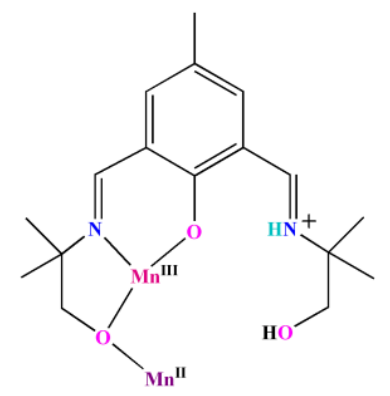

The core structure of $\mathbf{1}$ (Figure 2), elaborates the coordination connectivity, disposition of donor atoms and arrangement of the three manganese ions sitting within distorted octahedral geometry. Careful scrutiny of the bond distances (Table S2) around the terminal Mn ions (Mn1 and Mn1*) revealed them as $\mathrm{Mn}^{\mathrm{III}}$ centres, whereas the central $\mathrm{Mn}$ ion is assigned to $\mathrm{Mn}^{\mathrm{II}}$ centre. These oxidation states were further verified by a bond valence sum (BVS) analysis. ${ }^{42}$ The bond valence model is a popular method in coordination clusters to estimate the oxidation states of the metal ions present in the aggregate. ${ }^{43}$ The results of bond valence sums are summarized in Table S4 of SI. The tridentate $\mathrm{ONO}(\mathrm{O} 5 \mathrm{~N} 1 \mathrm{O} 6$ or $\mathrm{O} 5 * \mathrm{~N} 1 * \mathrm{O} 6 *)$ bite of the ligand along with the carboxylate $\mathrm{O} 2$ (or $\mathrm{O} 2 *$ ) forms the NO3 basal plane. For $\mathrm{Mn}^{\mathrm{III}}$ ions (Mn1 and Mn1*) the $\mathrm{Mn}-\mathrm{X}[\mathrm{X}=\mathrm{N}$ or O] bond distances along this basal plane varies from 1.867(3) to 1.992(4) $\AA$. The axial donor atoms from one carboxylate oxygen $\left(\mathrm{O} 13\right.$ or $\left.\mathrm{O} 13^{*}\right)$ and methanol oxygen $\left(\mathrm{O} 20\right.$ or $\left.\mathrm{O} 20^{*}\right)$ remain at 2.183(4) and 2.270(4) A. The central $\mathrm{Mn}^{\mathrm{II}}$ ion $(\mathrm{Mn} 2)$ records $\mathrm{Mn}-\mathrm{O}$ bond distances in the range 2.130(4)-2.147(3) $\AA$ along the basal plane and 2.193(4) $\AA$ along apical direction. Interestingly four acetato groups in $\mu_{1,3}$-bridging mode clearly established the basal-basal (O2-O3 and O2* $\mathrm{O} 3 *)$ and apical-basal (O13-O14 and $\mathrm{O} 13 *-\mathrm{O} 14 *)$ connectivity.

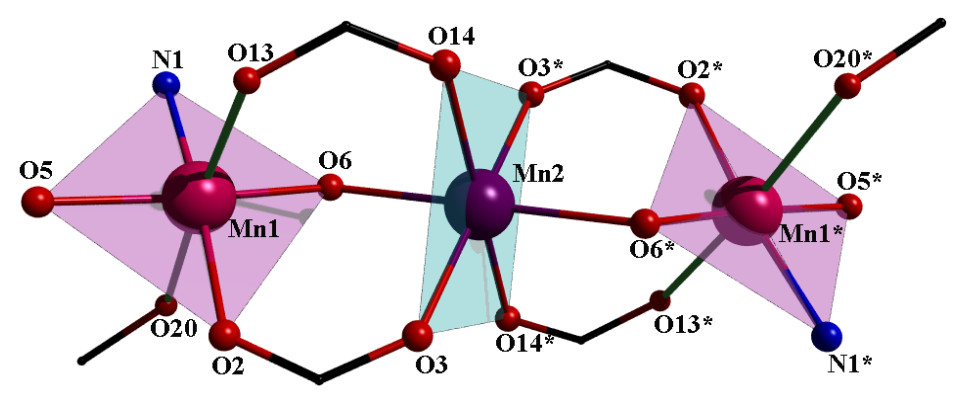

Figure 2. Core view of 1 . Color code: C, black; $\mathrm{N}$, blue; $\mathrm{O}$, red; $\mathrm{Mn}^{\mathrm{II}}$, purple; $\mathrm{Mn}^{\mathrm{III}}$, pink. 
The terminal phenoxido oxygen atom provides a six-membered chelate bite to the manganese ions giving $\mathrm{Mn}^{\mathrm{III}} \_\mathrm{O}$ separations of 1.900 (3) $\AA$, whereas the alkoxido end gives a five-membered chelate bite as well as extending bridging connectivity to the central $\mathrm{Mn}^{\mathrm{II}}$ ion. In this regard, oxygen atoms make $\mathrm{Mn}^{\mathrm{III}}-\mathrm{O}$ bonds of 1.867(3) $\AA$ and $\mathrm{Mn}^{\mathrm{II}}-\mathrm{O}$ bond of 2.147(3) $\AA$.

The lattice trapped solvent $\mathrm{MeOH}$ molecules serve as good hydrogen bond donors (D) to two of the carboxylate acceptors (A) involved in bridging. The protonated imine group (D) is also involved in hydrogen bonding interactions with the phenoxido oxygen (A). Such intramolecular

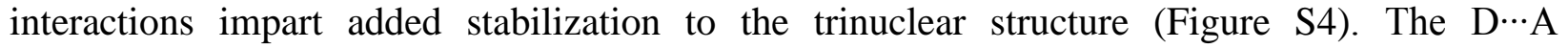
separations for $\mathrm{O} \cdots \mathrm{O}$ contacts vary from $2.781(7)$ to $2.787(5) \AA$ whereas that distance for $\mathrm{N} \cdots \mathrm{O}$ contacts is 2.674(5) $\AA$. The $\mathrm{D}-\mathrm{H} \cdots \mathrm{A}$ angles range from 115 to $165^{\circ}$ (Table S3).

$\left[\mathrm{Mn}_{6}\left(\mu_{4}-\mathrm{H}_{2} \mathrm{L2}\right)_{2}(\mu-\mathrm{HL} 3)_{2}\left(\mu_{3}-\mathrm{OH}\right)_{2}\left(\mu_{1,3}-\mathrm{O}_{2} \mathrm{CC}_{2} \mathrm{H}_{5}\right)_{4}\right]\left(\mathrm{ClO}_{4}\right)_{2} \cdot 2 \mathrm{H}_{2} \mathrm{O}$. Complex 2 crystallizes in the monoclinic $C 2 / c$ space group and the crystal data is summarized in Table 1. Significant bond distances and bond angles are listed in Table S1. The typical hexametallic pattern formed from binding of two each of two types of ligand system for $\mathbf{2}$ is shown in Figure 3. The molecule is symmetric with respect to a two-fold rotational axis of symmetry $(-x, y, 1 / 2-z)$ and half of the molecule constitutes the asymmetric unit.

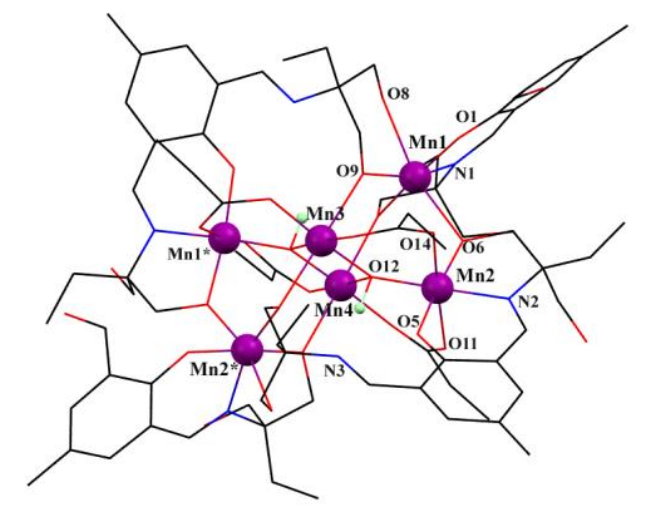

Figure 3. View of the complex unit in $\mathbf{2}$ with partial atom numbering. Counter ions are omitted for clarity. $\mathrm{H}$ atoms are shown only for $\mu_{3}-\mathrm{OH}$ groups. Color code: $\mathrm{C}$, black; H, pale green; Mn, purple; $\mathrm{N}$, blue; $\mathrm{O}$, red.

The entire structure of $\mathbf{2}$ is grown on two $\mathrm{H}_{2} \mathrm{~L}^{3-}$ groups and two of its hydrolysed congener $\mathrm{HL}^{2-}$. Each $\mathrm{H}_{2} \mathrm{~L}^{3-}$ shows a characteristic coordination mode to four different $\mathrm{Mn}$ centres through one imine $\mathrm{N}$, one non-bridging phenoxido $\mathrm{O}$, two bridging alkoxido $\mathrm{O}$ atoms and one terminal $\mathrm{OH}$ group. Two single arm hydrolysed ligands (HL3 ${ }^{2-}$ ) show a special type of 
coordination mode to two manganese ions through one imine $\mathrm{N}$, one non-bridging phenoxido $\mathrm{O}$ and one bridging alkoxido $\mathrm{O}$ atom (Chart II). The $\mathrm{O}$ atom of the $-\mathrm{CHO}$ group originating from hydrolysis remained as a pendant group without showing any kind of bonding to the manganese centres. Unlike the liberated 2-amino-2-ethylpropan-1,3-diol in the present case, the removed 2amino-2-methyl-1-propanol has been shown to stabilize nickel-based multimetallic aggregates, ${ }^{44}$ (Figure S5).

\section{Chart II. Unusual coordination modes of $\mathrm{H}_{5} \mathrm{~L} 2$ and $\mathrm{H}_{3} \mathrm{L3}$}
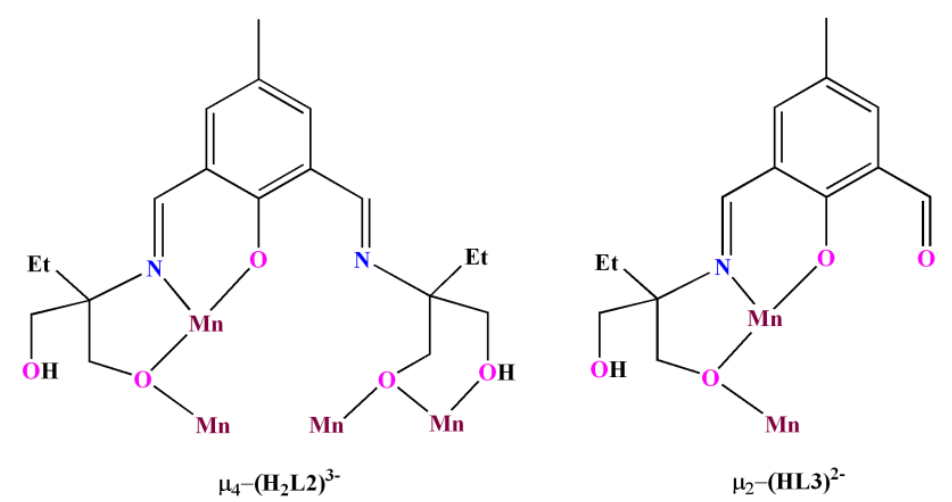

The six manganese centres are linked via two $\mu_{3}-\mathrm{OH}$ groups and four $\mu-\mathrm{O}_{2} \mathrm{CR}$ exogenous bridges. This hydroxido-carboxylato core is surrounded by four ligand units of two types (Figure 3). The hydroxido groups obtained from the solvent water molecules were crucial for the formation of $\left\{\mathrm{Mn}_{4}{ }_{4}{ }_{4}\left(\mu_{3}-\mathrm{OH}\right)_{2}\right\}$ type butterfly unit from fusion of two triangular subunits $\left\{\mathrm{Mn}_{3}{ }_{3}\left(\mu_{3}-\mathrm{OH}\right)\right\} .{ }^{45-47} \mathrm{The} \mathrm{Mn}-\mathrm{O}$ distances within this core range from $1.876(4)-2.250(4) \AA$. Within this butterfly unit the $\mathrm{O} 12$ and $\mathrm{O} 12 *$ atoms connect Mn2, Mn2*, Mn3 and Mn4. The fifth and sixth manganese centres (Mn1 and $\mathrm{Mn}^{*}$ ) sit on two sides of the triangular bases to provide the hitherto unknown fused-di-adamentane structure in manganese-carboxylate chemistry (Figure 4). Two $\mu_{3}-\mathrm{OH}$ groups (O12 and O12*) lie $0.125 \AA$ above and below the mean $\mathrm{Mn}_{4}$ plane consisting of Mn2, Mn2*, Mn3 and Mn4. In this structure the fifth and sixth Mn ${ }^{\mathrm{III}}$ ions $\left(\mathrm{Mn} 1\right.$ and $\left.\mathrm{Mn} 1^{*}\right)$ remain at $3.053 \AA$ apart from this plane. This recorded a separation of 3.181(5) $\AA$ for $\mathrm{O} 12-\mathrm{Mn} 1$ and $\mathrm{O} 12^{*}-\mathrm{Mn} 1 *$. This long separation thus prevented the possibility for further deprotonation from $\mu_{3}-\mathrm{OH}$ groups and resulting in the formation of a $\left\{\mathrm{Mn}_{4}\left(\mu_{4}-\mathrm{O}\right)\right\}$ complex as seen in $\mathrm{Cu}^{\mathrm{II}}$-carboxylate chemistry. ${ }^{48-49}$ Within the $\left\{\mathrm{Mn}_{4}\left(\mu_{3}-\mathrm{OH}\right)_{2}\right\}$ butterfly core the Mn3 $\cdots \mathrm{Mn} 4$ separation is shortest at $2.820 \AA$ compared to known reports for triangular fragments. ${ }^{50}$ The other manganese centres are separated from each other by the distances falling in the range 3.414 to 
$3.647 \AA$ (Figure S6). For oxido-bridged $\left\{\mathrm{Mn}_{3}^{\mathrm{III}}\left(\mu_{3}-\mathrm{O}\right)\right\}$ fragments the $\mathrm{Mn} \cdots \mathrm{Mn}$ separations remain in the range 3.143-3.414 $\AA^{51}$ and for complexes containing $\left\{\mathrm{Mn}_{4}\left(\mu_{4}-\mathrm{O}\right)\right\}$ cores the

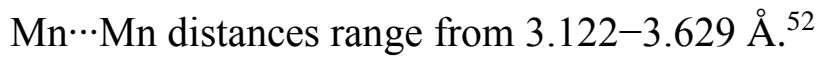
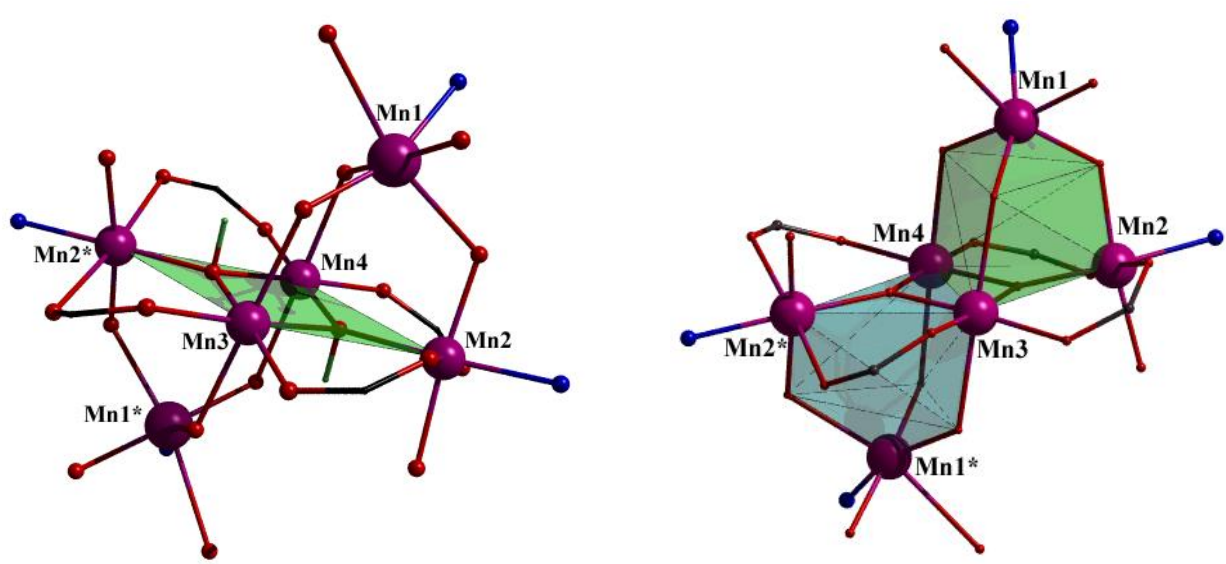

Figure 4. Fused-diadamantane like arrangement in $\mathbf{2}$.

Four manganese ions (Mn1, Mn1*, Mn2 and $\mathrm{Mn}^{*}$ ) have primary coordination from the anionic ligand part or its hydrolysed congener. This has been evidenced from the four $\mathrm{Mn}-\mathrm{N}$ bonds, from the imine $\mathrm{N}$ atoms, within 2.008(6) to 2.018(6) $\AA$. The other two manganese ions (Mn3 and Mn4) did not show any primary coordination to ligand systems except hydroxido, carboxylato, alkoxido and alcohol coordination in the 1.876(4) to 2.250(4) $\AA$ range. Among these alcohol O atoms showed longest distances and phenoxido $\mathrm{O}$ atoms register shortest within this group. The fused-di-adamentane structure has a unique $\left[\mathrm{Mn}_{6}(\mathrm{OH})_{2} \mathrm{O}_{6}\right]$ core (Figure 5) hitherto unknown in the literature. The bond valence model has been used to analyse the number of electrons each atom contributes to the coordinate bonds formed. The BVS calculations (Table S4) assigned the oxidation state to all manganese ions as $\mathrm{Mn}^{\mathrm{III}}$. In distorted octahedral environments two types of manganese centres are present in this complex: $\left[\mathrm{MnO}_{5} \mathrm{~N}\right]$ and $\left[\mathrm{MnO}_{6}\right]$. Two $\left(\mathrm{Mn} 1, \mathrm{Mn} 1^{*}\right)$ and four $(\mathrm{Mn} 2, \mathrm{Mn} 2 *)$ different $\mathrm{Mn}-\mathrm{O}$ bonds were seen with the $\left[\mathrm{MnO}_{5} \mathrm{~N}\right]$ type and the $\left[\mathrm{MnO}_{5} \mathrm{~N}\right]$ type showed three different types of Mn-O bonds (Table 1). 


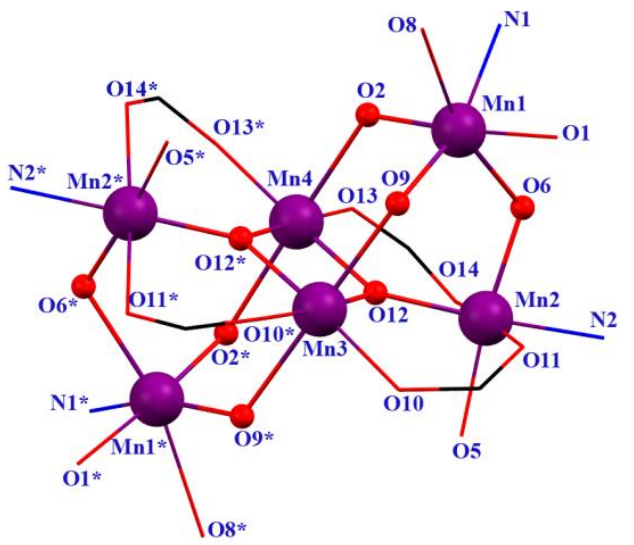

Figure 5. Core view of 2. Color code: C, black; Mn, purple; O, red; N. blue.

Table 1. The types of $\mathrm{Mn}-\mathrm{O}$ and $\mathrm{Mn}-\mathrm{N}$ bonds in 2.

\begin{tabular}{|c|c|c|c|}
\hline $\begin{array}{l}\text { Coordination } \\
\text { environment }\end{array}$ & Metal ions & Donor atoms & Bond distances $(\AA)$ \\
\hline \multirow[t]{3}{*}[\mathrm{MnO}_{5}\mathrm{N}]{} & \multirow[t]{3}{*}{ Mn1 and Mn1* } & Mn-O(phenoxido) & $1.889(5)$ \\
\hline & & Mn-O(alkoxido) & $1.884(5)-2.420(5)$ \\
\hline & & Mn-N(imine) & $2.018(6)$ \\
\hline \multirow[t]{5}{*}[\mathrm{MnO}_{5}\mathrm{N}]{} & \multirow[t]{5}{*}{ Mn2 and $\mathrm{Mn} 2 *$} & $\mathrm{Mn}-\mathrm{O}($ phenoxido $)$ & $1.931(4)$ \\
\hline & & Mn-O(hydroxido) & $1.886(4)$ \\
\hline & & $\mathrm{Mn}-\mathrm{O}$ (alkoxido) & $1.876(4)$ \\
\hline & & $\mathrm{Mn}-\mathrm{O}$ (carboxylato) & $2.193(5)-2.213(5)$ \\
\hline & & Mn-N(imine) & $2.008(6)$ \\
\hline \multirow[t]{3}{*}[\mathrm{MnO}_{6}]{} & \multirow[t]{3}{*}{ Mn3 and Mn4 } & Mn-O(hydroxido) & $1.876(4)$ \\
\hline & & Mn-O(alkoxido) & $2.241(4)-2.250(4)$ \\
\hline & & $\mathrm{Mn}-\mathrm{O}$ (carboxylato) & $1.958(5)-1.959(5)$ \\
\hline
\end{tabular}

Each $\mathrm{H}_{3} \mathrm{~L}_{2}{ }^{2-}$ and $\mathrm{HL}_{3}{ }^{2-}$ has one dangling alcohol group not bound to any metal ions and actively participates in hydrogen bonding interactions. They form intermolecular hydrogen bonds with two lattice trapped water molecules resulting in an infinite 3D network (Figure S7). The characteristic hydrogen bonding parameters are listed in Table S3. The perchlorate counter anions are trapped within this H-bonded 3D network. D $\cdots A$ distances vary from 2.746(15) to 3.313(15) $\AA$ and the $\mathrm{D}-\mathrm{H} \cdots \mathrm{A}$ angles range from 110 to $157^{\circ}$.

Magnetic Properties. The temperature dependence of the molar magnetic susceptibility, $\chi_{\mathrm{M}}$, of compounds 1 and 2 was measured under a magnetic field of $0.1 \mathrm{~T}$ over the temperature range 
$290-1.8 \mathrm{~K}$ (Figure 6). At $290 \mathrm{~K}$, the values of $\chi_{\mathrm{M}} T$ for 1 and 2 are 8.80 and $11.40 \mathrm{~cm}^{3} \mathrm{~mol}^{-1} \mathrm{~K}$, respectively. These values are significantly below than expected theoretically for the compounds (10.38 $\mathrm{cm}^{3} \mathrm{~mol}^{-1} \mathrm{~K}$ for $\mathbf{1}$, and $18.00 \mathrm{~cm}^{3} \mathrm{~mol}^{-1} \mathrm{~K}$ for $\mathbf{2}$, assuming $g=2.0$ in both cases), consistent with dominant intramolecular antiferromagnetic exchange interactions. On decreasing the temperature, $\chi_{\mathrm{M}} T$ decreases continually for both the compounds. Below $20 \mathrm{~K}$, a small plateau is observed in $\chi_{\mathrm{M}} T$ for $\mathbf{1}$, before a final, sharp decrease to $1.34 \mathrm{~cm}^{3} \mathrm{~mol}^{-1} \mathrm{~K}$ at $1.8 \mathrm{~K}$. Compound 2 presents a continual decrease in $\chi_{\mathrm{M}} T$ reaching a minimum value of $0.66 \mathrm{~cm}^{3} \mathrm{~mol}^{-1} \mathrm{~K}$ at $2.0 \mathrm{~K}$. Field-dependent magnetisation measurements were performed for compound 1 at 2, 4, and $6 \mathrm{~K}$ (Figure 7). The magnetisation does not saturate at the highest measured field of $5 \mathrm{~T}$, indicating the presence of magnetic anisotropy arising from the Mn(III) ions.

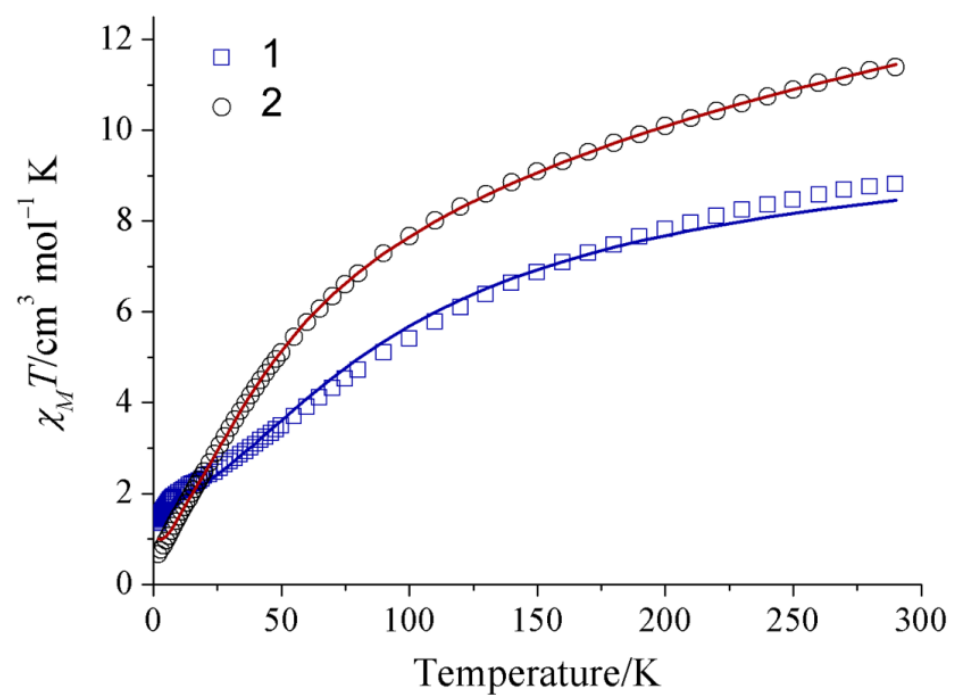

Figure 6. Plots of $\chi_{\mathrm{M}} T$ vs. $T$ for $\mathbf{1}$ and $\mathbf{2}$. The solid lines correspond to fits of the data (see text for details).

The magnetic data for $\mathbf{1}$ and $\mathbf{2}$ were fitted using the program Phi $2.0 .^{53}$ For compound $\mathbf{1}$, it was possible to simultaneously fit both the $\chi_{\mathrm{M}} T$ and magnetisation data. One coupling constant, $J_{1}$, was considered between the outer Mn(III) ions and the central Mn(II) ion (see inset of Figure 7), and the $g$-value was fixed at 2.0. Any possible exchange interaction between the outer $\mathrm{Mn}$ (III) ions was neglected, based on previous studies. ${ }^{54,55}$ The single-ion axial zero-field splitting parameter $d$ was included in the fit for both $\mathrm{Mn}(\mathrm{III})$ ions. An intermolecular interaction $z J^{\prime}$ of $0.02 \mathrm{~cm}^{-1}$ and a temperature-independent paramagnetism (TIP) contribution of $3.2 \cdot 10^{-6} \mathrm{~cm}^{3}$ mol $^{-1}$ were also included. ${ }^{56}$ The Hamiltonian used was as follows 


$$
\widehat{\mathcal{H}}=-2 \mathcal{J}_{1}\left(\hat{S}_{1} \hat{S}_{2}+\hat{S}_{2} \hat{S}_{3}\right)+g \mu_{B} \vec{B} \sum_{i=1}^{3} \overrightarrow{S_{l}}+d_{1}\left(\hat{S}_{1 z}^{2}-\frac{1}{3} S_{1}\left(S_{1}+1\right)\right)+d_{3}\left(\hat{S}_{3_{z}}^{2}-\frac{1}{3} S_{3}\left(S_{3}+1\right)\right)
$$

and the results of the fit are shown as solid lines in Figures 6 and 7. The fitting process yielded a value of $J_{1}=-5.95 \mathrm{~cm}^{-1}$, and a value of $d_{i}$ for each $\mathrm{Mn}$ (III) ion of $-2.25 \mathrm{~cm}^{-1}(R=97 \%)$. These results are consistent with the relatively large $\mathrm{Mn}-\mathrm{O}-\mathrm{Mn}$ angle $\left(120.37(14)^{\circ}\right)$ bridging the $\mathrm{Mn}(\mathrm{III})$ and $\mathrm{Mn}(\mathrm{II})$ ions, and with the observed tendency of acetate-bridged $\left\{\mathrm{Mn}^{\mathrm{III}}{ }_{2} \mathrm{Mn}^{\mathrm{II}}\right\}$ complexes to display antiferromagnetic coupling. ${ }^{57}$ The tetragonal elongation around the Mn(III) ions is conducive to negative values of $d_{i .}{ }^{58}$

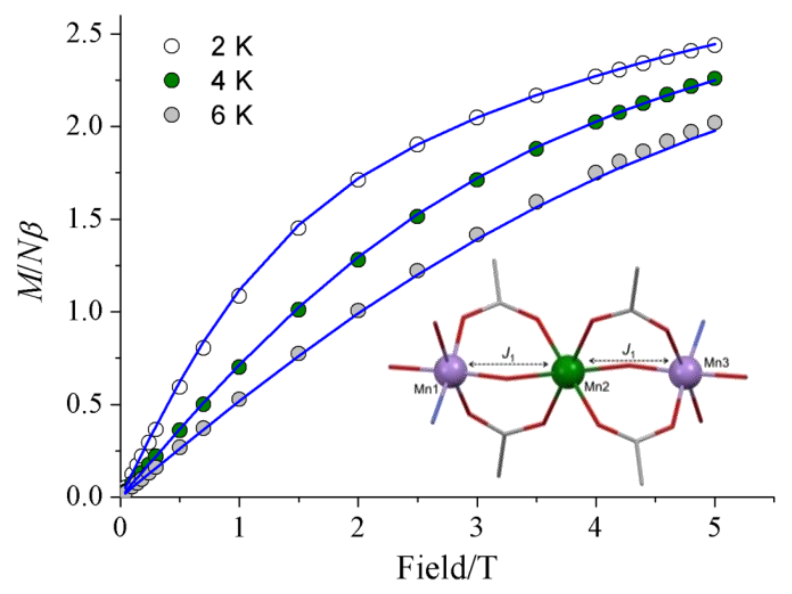

Figure 7. Plots of $M$ vs. $H$ for $\mathbf{1}$. The solid lines correspond to the fit of the data (see text for details), and the inset shows the model considered.

Given the axial anisotropy of the Mn(III) ions determined by the $d c$ magnetic studies for $\mathbf{1}$, ac susceptibility measurements were performed to ascertain whether the complex displays slow relaxation of the magnetisation. In zero dc field, no out-of-phase component to the susceptibility, $\chi^{\prime \prime}$, was observed (Figure S8). Application of a static field of $H=2000$ Oe was shown to allow measurement of the onset of slow magnetic relaxation at $2 \mathrm{~K}$. A subsequent field sweep at $2 \mathrm{~K}$ showed that applied fields as low as 500 Oe were sufficient to bring about an appreciable component to the out-of-phase susceptibility (Figure S9), however any maxima were beyond the frequency range of the magnetometer and the data were not analysed further. 
We have also used DFT calculations using the broken symmetry approach to estimate the magnetic coupling constant $J$ in $\mathbf{1}$ using the crystallographic coordinates. The theoretical value of $J\left(-6.07 \mathrm{~cm}^{-1}\right)$ calculated at the B3LYP/6-31G* level of theory is in excellent agreement with the experimental value $\left(-5.95 \mathrm{~cm}^{-1}\right)$ and confirms the antiferromagnetic coupling. With an aim to investigate mechanism for the magnetic exchange coupling, the spin density distribution has been analysed. The atomic spin population values on the Mn metal centers and the donor atoms of the ligands are listed in Table S5. The Mulliken spin population analysis for the high-spin (HS) configuration shows that some spin (ca. $0.38 \mathrm{e}$ ) is delocalized through the ligands, and the rest (12.62 e) is supported by the Mn ions. The representation of the spin distributions relating to one of the "broken-symmetry" wavefunction and the high spin states for complex $\mathbf{1}$ are described in Figure 8, where $\alpha$ and $\beta$ spin states are denoted by positive (blue) and negative (green) signs, respectively. The broken-symmetry spin population values of +3.84 on $\mathrm{Mn}(\mathrm{III})$ and -4.81 on $\mathrm{Mn}$ (II) confirms the centres to be magnetic centres and that the spin delocalization is modest ( $2.7 \%$ of the spin arising from the unpaired electrons on the $\mathrm{Mn}^{\mathrm{II}} / \mathrm{Mn}^{\mathrm{III}}$ centres is delocalized to the ligand framework). The spin population on the donor atoms have the same sign as that of the Mn atoms to which they are bonded (see Table S5). Remarkably, the spin on the acetate O atoms $(\mathrm{O} 13 / \mathrm{O} 14)$ is $c a .0 .08 \mathrm{e}$ in the HS state and $-0.01 \mathrm{e}$ in the broken-symmetry state of complex $\mathbf{1}$. In contrast the spin density is almost negligible on the alkoxide atoms. Consequently, the bridging oxygens of acetate are more effective in mediating the magnetic exchange. 

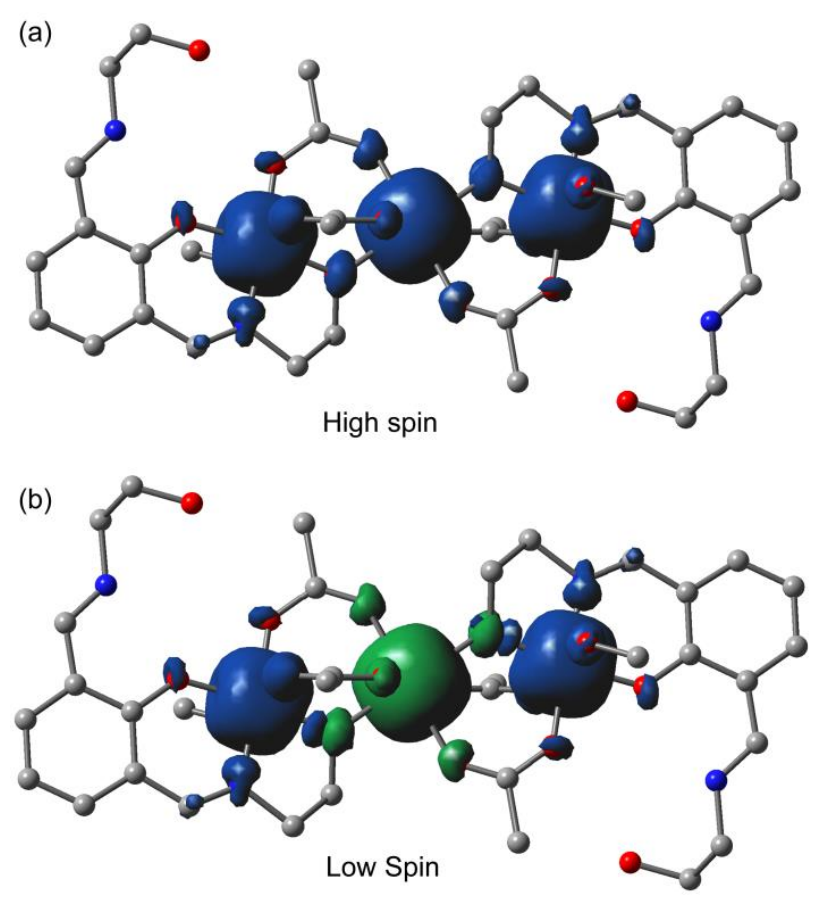

Figure 8. Graphical representation of spin density (contour $0.004 \mathrm{e} \AA^{-3}$ ) at the high spin (a) and low spin (b) configurations of complex $\mathbf{1}$.

Compound 2 contains two edge-sharing tetrahedra of $\mathrm{Mn}(\mathrm{III})$ ions, with $\mathrm{Mn} 1$ sitting above a basal-plane formed by Mn2, Mn3 and Mn4, with the latter two ions forming the shared edge. To fit the data, four different coupling constants were considered: $J_{1}$ for the interaction between Mn1 and Mn2; $J_{2}$ for the exchange between Mn1 and both Mn3 and Mn4; $J_{3}$ for the coupling between Mn2 and both Mn3 and Mn4; and $J_{4}$ for the interaction between Mn3 and Mn4 (Figure 9). The $g$-value for the ions was fixed at 2.0, and any axial anisotropy associated with the six $\mathrm{Mn}(\mathrm{III})$ ions was omitted to reduce the number of parameters in the fit. The Hamiltonian used for the fit was as follows, where asterisks represent symmetry equivalent sites,

$$
\begin{aligned}
\widehat{\mathcal{H}}=-2 J_{1}\left(\hat{S}_{1} \hat{S}_{2}+\hat{S}_{1^{*}} \hat{S}_{2^{*}}\right)-2 J_{2}\left(\hat{S}_{1} \hat{S}_{3}+\hat{S}_{1} \hat{S}_{4}+\hat{S}_{1^{*}} \hat{S}_{3}+\hat{S}_{1^{*}} \hat{S}_{4}\right) \\
\quad-2 J_{3}\left(\hat{S}_{2} \hat{S}_{3}+\hat{S}_{2} \hat{S}_{4}+\hat{S}_{2^{*}} \hat{S}_{3}+\hat{S}_{2^{*}} \hat{S}_{4}\right)-2 \mathcal{J}_{4}\left(\hat{S}_{3} \hat{S}_{4}\right)+g \mu_{B} \vec{B} \sum_{i=1}^{6} \overrightarrow{S_{l}}
\end{aligned}
$$



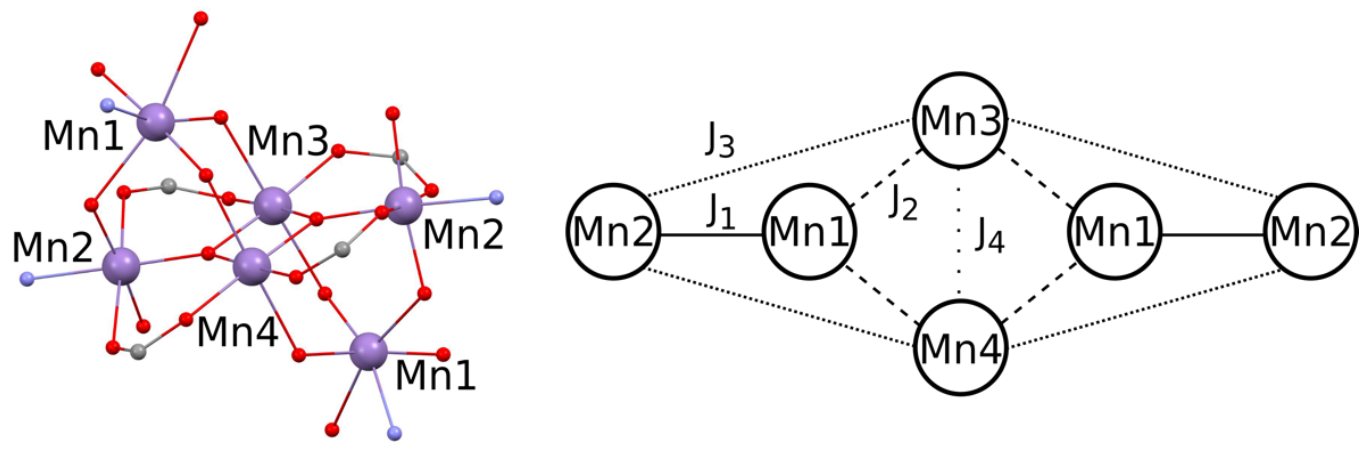

Figure 9. (Left) View of the connectivity of the $\mathrm{Mn}(\mathrm{III})$ ions in 2, and (right) a schematic of the exchange interactions used for the fitting process. For clarity, equivalent interactions are shown with the same type of lines.

The fit of $\chi_{\mathrm{M}} T v s . T$ yielded $J_{1}=-5.99 \mathrm{~cm}^{-1} ; J_{2}=-2.40 \mathrm{~cm}^{-1} ; J_{3}=-11.09 \mathrm{~cm}^{-1}$; and $J_{4}=-23.75$ $\mathrm{cm}^{-1}(R=99 \%)$. The strongest interaction is found between Mn3 and Mn4, consistent with data in the literature. The coupling in this type of butterfly arrangement, where Mn3 and Mn4 define the body and both Mn2 ions define the wings, is found to depend on the oxidation state of the ions in the wings. ${ }^{59}$ When both ions in the wings are $\mathrm{Mn}(\mathrm{III})$, as is the case here, then the exchange between the two $\mathrm{Mn}$ (III) ions in the body is usually antiferromagnetic with values below $-20 \mathrm{~cm}^{-1}{ }^{60-64}$ The exchange interactions between Mn1 and Mn2, and between Mn1 and Mn3 and Mn4, all occur through monoatomic alkoxido bridges. However, the Mn-O-Mn angle is different in the two cases, measuring $117.4(2)^{\circ}$ for the angle between $\mathrm{Mn} 1$ and $\mathrm{Mn} 2$, and 121.4(2) and $122.8(2)^{\circ}$ for the angles between Mn1 and Mn3, and Mn1 and Mn4, respectively. The distance between $\mathrm{Mn} 1$ and $\operatorname{Mn} 2(3.508 \AA)$ is also significantly shorter than the distance between Mn1 and Mn3 (3.647 ̊), and Mn1 and Mn4 (3.626 ̊̊). This could explain the stronger interaction $J_{1}$ between Mn1 and Mn2 compared to that between Mn1 and Mn3 and Mn4, $J_{2}$. For interatomic distances above $3.6 \AA$ and $\mathrm{Mn}-\mathrm{O}-\mathrm{Mn}$ angles above $120^{\circ}$, the coupling has been found to be around $-2 \mathrm{~cm}^{-1}$, in line with that found here for $J_{2}{ }^{65}$ The coupling constant $J_{2}$ lies in the range of that found for other similarly connected $\mathrm{Mn}(\mathrm{III})$ ions in the literature. ${ }^{64,66}$

We have also computed using DFT calculations the coupling constants in the hexanuclear complex 2. They are presented in Table 2 and a good agreement between the theoretical and experimental values is observed, thus confirming the antiferromagnetic coupling constants $J_{1}$ to 
$J_{4}$ and giving reliability to the Hamiltonian used for the fitting and also the level of theory used for the calculations. The atomic spin density values of the Mn centers and the donor atoms of the ligands are summarized in Table S6 for the four pairwise magnetic coupling interactions. Moreover, the representation of the spin distribution corresponding to the high spin state of complex 2 is plotted in Figure S10. The spin population values in the four $\left[\mathrm{Mn}_{2}\right]$ dimers reveal that most of the spin is carried by the Mn(III) magnetic centres and that the spin delocalization is small (from $2.25 \%$ to $2.75 \%$ of the spin for the unpaired electrons on $\mathrm{Mn}$ (III) centres is delocalized to the ligand atoms, depending on the pairwise interaction). Remarkably, the spin carried by the alkoxido atom $\mathrm{O} 6$ is higher than $\mathrm{O} 9$, in agreement with the stronger interaction $J_{1}$ between Mn1 and Mn2 (via O6) compared to that between Mn1 and Mn3 (via O9), $J_{2}$. The spin population also reveals that the exchange interaction between Mn2 and Mn3 occurs through the carboxylate bridges.

Table 2. Summary of the experimental and theoretical (B3LYP/6-31G*) magnetic coupling constants $\left(J, \mathrm{~cm}^{-1}\right)$

\begin{tabular}{|l|c|c|c|}
\hline compound & $J$ & Experimental & Theoretical \\
\hline $\mathbf{1}$ & $J_{1}\left(\mathrm{Mn}^{\mathrm{III}}-\mathrm{Mn}^{\mathrm{II}}\right)$ & -5.95 & -6.07 \\
\hline $\mathbf{2}$ & $J_{1}(\mathrm{Mn} 1-\mathrm{Mn} 2)$ & -5.99 & -6.55 \\
\hline $\mathbf{2}$ & $J_{2}(\mathrm{Mn} 1-\mathrm{Mn} 3)$ & -2.40 & -4.77 \\
\hline $\mathbf{2}$ & $J_{3}(\mathrm{Mn} 2-\mathrm{Mn} 3)$ & -11.09 & -14.01 \\
\hline $\mathbf{2}$ & $J_{4}(\mathrm{Mn} 3-\mathrm{Mn} 4)$ & -23.75 & -28.40 \\
\hline
\end{tabular}

Functional Activity for Catechol Oxidation. The catalytic oxidation behaviour of complexes 1 and 2 were examined in aerobic conditions using 3,5-di-tert-butylcatechol (3,5-DTBCH$)$ as a model prototypical catechol oxidase substrate. The tert-butyl substituents at the 3 and 5 positions of the aromatic ring makes the oxidation reaction feasible forming 3,5-di-tert-butylquinone $(3,5$ DTBQ) in $\mathrm{MeOH}$ and $\mathrm{MeCN}$ having absorption maxima at $401 \mathrm{~nm}$ and $403 \mathrm{~nm}$, respectively. Solutions of complexes 1 and $2\left(\sim 1 \times 10^{-5} \mathrm{~mol} \mathrm{~L}^{-1}\right)$ were treated with 100 equivalents $\left(\sim 1 \times 10^{-3}\right.$ mol L ${ }^{-1}$ ) of 3,5-DTBCH 2 under aerobic conditions in two different solvents ( $\mathrm{MeOH}$ and $\left.\mathrm{MeCN}\right)$ and time-dependent UV-vis spectra were recorded up to $1 \mathrm{~h}$. Control experiments were performed 
using manganese(II) perchlorate and 100 eq $\mathrm{DTBCH}_{2}$ where no change was observed in absorption intensity even after one day.

Oxidation in $\mathrm{MeOH}$. Both 1 and 2 behave in a similar fashion during catalytic oxidation of $\mathrm{DTBCH}_{2}$. Figure 10 shows the changes in spectral behaviour of the two complexes on treatment with $\mathrm{DTBCH}_{2}$. The oxidation reaction was followed for $1 \mathrm{~h}$, after addition of the substrate $\mathrm{DTBCH}_{2}$. Initially both the complexes show a broad absorption band centered at $405 \mathrm{~nm}$ in $\mathrm{MeOH}$. After addition of $\mathrm{DTBCH}_{2}$ the band instantly shifts to longer wavelength ( 430 nm for 1 and $\sim 413 \mathrm{~nm}$ for 2) with the generation of a shoulder at $\sim 309 \mathrm{~nm}$. As time passes, the former band gradually blue shifts and finally becomes stabilized at $404 \mathrm{~nm}$ and $402 \mathrm{~nm}$ for $\mathbf{1}$ and $\mathbf{2}$, respectively. The shoulder at $309 \mathrm{~nm}$ on the other hand gradually disappears with the progress of the reaction with time. This observation of appearance and disappearance of the shoulder peak can be explained by taking into consideration of the initial formation of a catalyst-substrate adduct which decomposes with time upon generation of the stable oxidized product DTBQ. ${ }^{67}$
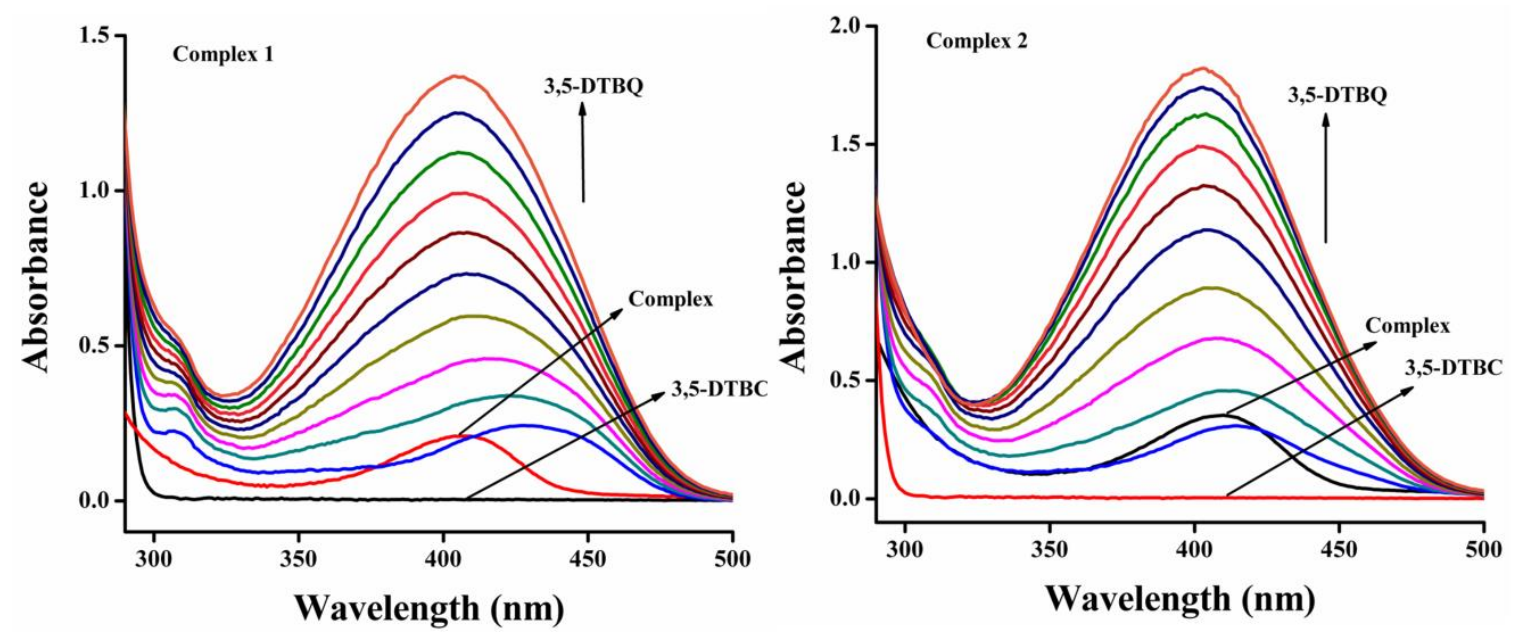

Figure 10. Time dependent UV-vis spectral changes for $\mathbf{1}$ and $\mathbf{2}$ (concentration $\sim 1 \times 10^{-5} \mathrm{~mol} \mathrm{~L}^{-1}$ ) upon addition of excess of (100 fold) 3,5-DTBCH ${ }_{2}$ (concentration $\sim 1 \times 10^{-3} \mathrm{~mol} \mathrm{~L}^{-1}$ ) in $\mathrm{MeOH}$ at $298 \mathrm{~K}$.

Oxidation in MeCN. The catalytic oxidation potency of $\mathbf{1}$ and $\mathbf{2}$ in air has been studied and compared in MeCN medium to identify the solvent effect in the oxidation process. Upon treatment of $\mathbf{1}$, having an absorption maximum at $392 \mathrm{~nm}$, with $100 \mathrm{eq} \mathrm{DTBCH}_{2}$, the intensity of maximum absorption increases significantly in favour of $\mathbf{1}$ to be identified as a catalyst for the aerobic oxidation of DTBC to DTBQ (Figure 11). The reaction was monitored by UV-vis spectrophotometry up to $1 \mathrm{~h}$ time, showing saturation after $45 \mathrm{~min}$ of addition of $\mathrm{DTBCH}_{2}$. 
Unlike the $\mathrm{MeOH}$ case, the $\mathrm{MeCN}$ medium did not show any additional absorption band characteristic of any complex- substrate (CS) aggregate, possibly due to the involvement of a fast kinetic process during the oxidation of $3,5-\mathrm{DTBCH}_{2}$ to $3,5-\mathrm{DTBQ}$. We also observed that complex $\mathbf{2}$ is catalytically inactive in $\mathrm{MeCN}$ medium. Initially complex $\mathbf{2}$ shows an absorption band at $409 \mathrm{~nm}$, which upon addition of 3,5- $\mathrm{DTBCH}_{2}$, registers a quenching in maxima at 411 $\mathrm{nm}$. Most probably this is due to the weak interaction of $\mathbf{2}$ with the substrate molecule, i.e., adduct formation in $\mathrm{MeCN}$, not the expected oxidation behavior.
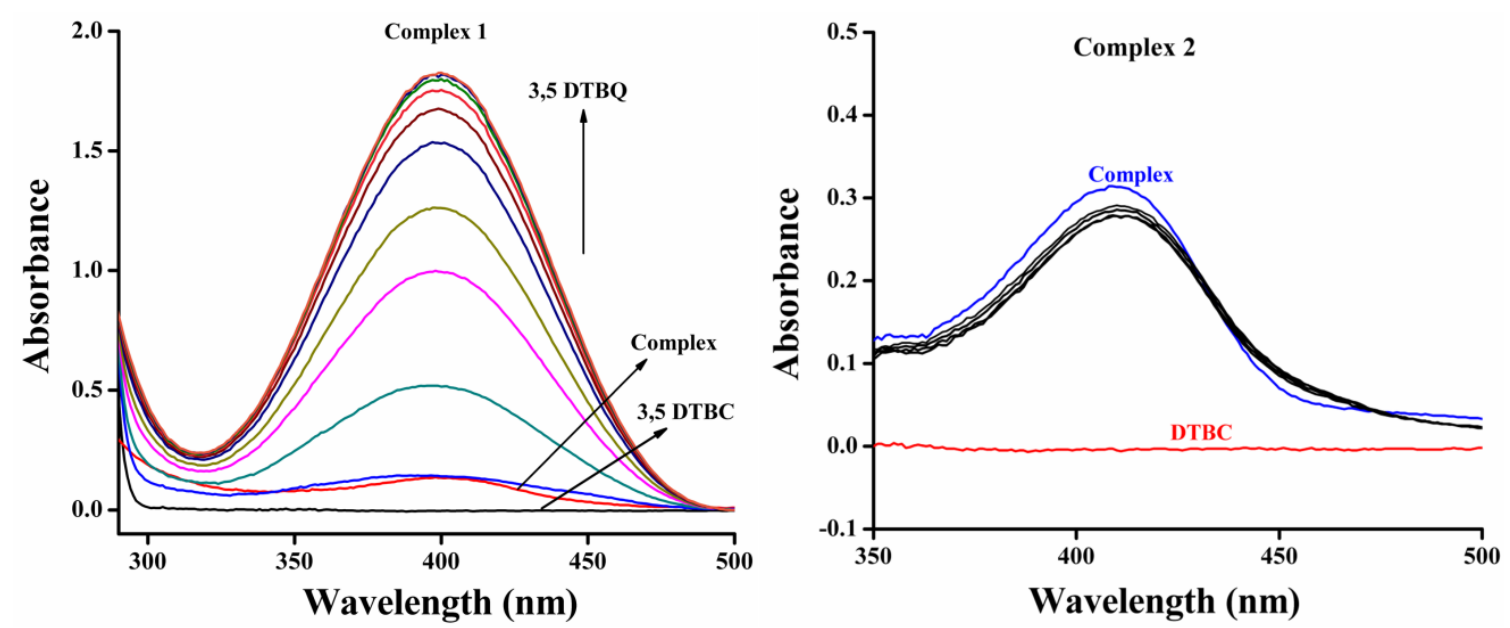

Figure 11. Time dependent UV-vis spectra of complexes 1 and 2 (conc. $\sim 1 \times 10^{-5} \mathrm{~mol} \mathrm{~L}^{-1}$ ) after addition of excess of (100 fold) 3,5-DTBCH 2 (conc. $\sim 1 \times 10^{-3} \mathrm{~mol} \mathrm{~L}^{-1}$ ) in $\mathrm{MeCN}$ at $298 \mathrm{~K}$.

Kinetic study for catechol Oxidation. Kinetic evaluation for the oxidation of 3,5-- $\mathrm{DTBCH}_{2}$ in the presence of $\mathbf{1}$ and $\mathbf{2}$ were carried out in $\mathrm{MeOH}$ for both $\mathbf{1}$ and $\mathbf{2}$ and in $\mathrm{MeCN}$ for $\mathbf{1}$ only. In all cases the complex solutions (fixed concentration $\sim 1 \times 10^{-5} \mathrm{~mol} \mathrm{~L}^{-1}$ ) were treated with varying concentrations of 3,5-DTBC (10 to 100 equivalent). For all 'complex-substrate' combinations, the formation of DTBQ was monitored by UV-vis spectrophotometry by recording the change in absorption intensity at $401 \mathrm{~nm}$ in $\mathrm{MeOH}$ and at $403 \mathrm{~nm}$ in $\mathrm{MeCN}$ within first $10 \mathrm{~min}$ of mixing. The reaction rates were calculated by initial rate method and were analyzed by the MichaelisMenten model of enzyme kinetics. In all cases the important kinetic parameters were extracted from the corresponding Lineweaver-Burk plots for all cases (Figure 12 and 13 insets). The kinetic parameters such as, the maximum reaction rate $\left(V_{\max }\right)$, the binding constant $\left(K_{M}\right)$ and the turnover numbers $\left(k_{c a t}\right)$ for the oxidation reaction are listed in Table 3. The magnitude of $K_{M}$ 
shows the concentration of the substrate when the reaction velocity is equal to one half of the maximal velocity for the reaction. It can also be a measure of the binding affinity for the substrate. The observed kinetic parameters are comparable to that reported in the literature (Table S7). ${ }^{68-72}$ Determination of turnover number $\left(k_{c a t}\right)$ of the metal complexes is important to understand their relative efficiency. The experiments for the detection of formed $\mathrm{H}_{2} \mathrm{O}_{2}$ in the reaction medium following iodometric method did not provide any proof in support of formation of $\mathrm{I}_{2}$ in the medium, excluding the possibility of formation of $\mathrm{H}_{2} \mathrm{O}_{2}$ during the catalytic process.

Table 3. Kinetic parameters for the catalytic oxidation of 3,5-DTBCH $\mathrm{D}_{2}$ by $\mathbf{1}$ and $\mathbf{2}$ at $25^{\circ} \mathrm{C}$

\begin{tabular}{|c|c|c|c|c|c|}
\hline Complex & Solvent & $V_{\max }\left(\mathrm{M} \mathrm{s}^{-1}\right)$ & $K_{M}(\mathrm{M})$ & $k_{c a t}\left(\mathrm{~h}^{-1}\right)$ & $k_{c a} / K_{M}\left(s^{-1} M^{-1}\right)$ \\
\hline $\mathbf{1}$ & $\mathrm{MeOH}$ & $(1.71 \pm 0.05) \times 10^{-7}$ & $(1.04 \pm 0.04) \times 10^{-4}$ & 61 & 162 \\
\hline $\mathbf{2}$ & $\mathrm{MeOH}$ & $(1.52 \pm 0.03) \times 10^{-7}$ & $(7.79 \pm 0.49) \times 10^{-5}$ & 54 & 192 \\
\hline $\mathbf{1}$ & $\mathrm{MeCN}$ & $(1.79 \pm 0.05) \times 10^{-6}$ & $(3.44 \pm 0.03) \times 10^{-4}$ & 644 & 520 \\
\hline
\end{tabular}
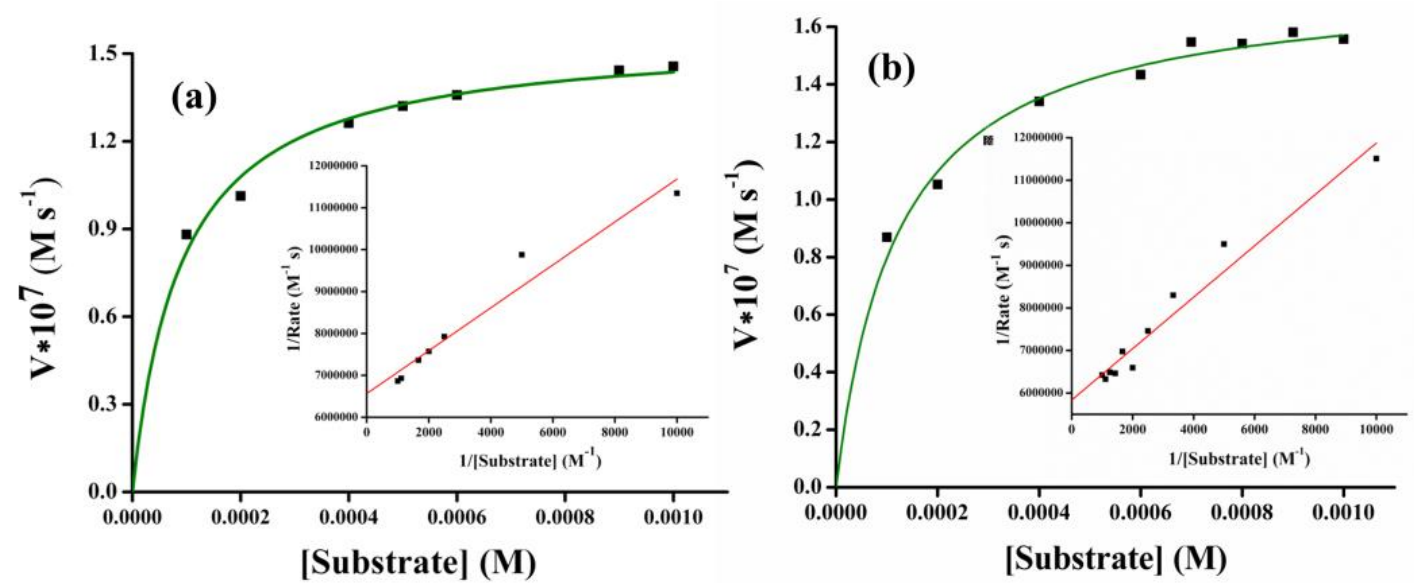

Figure 12. Dependence of the reaction rates on the substrate concentration for the oxidation of 3,5-DTBCH 2 catalyzed by complexes $\mathbf{1}$ (a) and $\mathbf{2}$ (b) in $\mathrm{MeOH}$. The Lineweaver-Burk plots (inset). 


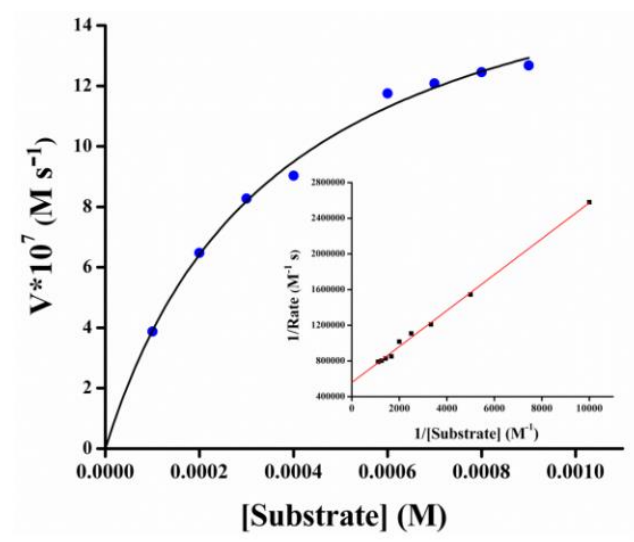

Figure 13. Dependence of the reaction rates on the substrate concentration for the oxidation of 3,5-DTBCH catalyzed by 1 in MeCN. The Lineweaver-Burk plot (inset).

Mass Spectroscopic Analysis. To understand the nature of the fragments present in the two solvents used in this study and their dependence on the catalytic propensity, we have scrutinized corresponding mass spectral patterns in $\mathrm{MeOH}$ and $\mathrm{MeCN}$.

Fragments in MeOH. The mass spectrum (HRMS) of 1 (Figure S11) shows five peaks of medium to high intensity types at $\mathrm{m} / \mathrm{z}$ values of $236.1284,307.2021,329.0687,405.1249$ and 523.1647. Based on the calculated $\mathrm{m} / \mathrm{z}$ values these peaks can be assigned to the fragments [hydrolysed- $\left.\mathrm{H}_{2} \mathrm{~L} 1\right] \mathrm{H}^{+} \quad\left(\mathrm{C}_{13} \mathrm{H}_{18} \mathrm{NO}_{3} ; \quad\right.$ Calcd. 236.1287), $\quad\left[\mathrm{H}_{3} \mathrm{~L} 1-\mathrm{H}\right]^{+} \quad\left(\mathrm{C}_{17} \mathrm{H}_{27} \mathrm{~N}_{2} \mathrm{O}_{3} ; \quad\right.$ Calcd. 307.2022), $\quad\left[\mathrm{H}_{3} \mathrm{~L} 1-\mathrm{Na}\right]^{+} \quad\left(\mathrm{C}_{17} \mathrm{H}_{26} \mathrm{~N}_{2} \mathrm{NaO}_{3} ; \quad\right.$ Calcd. 329.1841), [Mn(hydrolysed$\mathrm{HL} 1)\left(\mathrm{O}_{2} \mathrm{CCH}_{3}\right)\left(\mathrm{OH}_{2}\right)-\mathrm{K}^{+}\left(\mathrm{C}_{15} \mathrm{H}_{21} \mathrm{KMnNO}_{6}\right.$; Calc. 405.0386) and $\left[\mathrm{Mn}(\mathrm{HL} 1)\left(\mathrm{O}_{2} \mathrm{CCH}_{3}\right)_{2}-\mathrm{Na}_{2}\right]^{+}$ $\left(\mathrm{C}_{21} \mathrm{H}_{30} \mathrm{MnN}_{2} \mathrm{Na}_{2} \mathrm{O}_{7}\right.$; Calc. 523.1229), respectively. The mixture of 1 and 3,5-DTBCH 2 in 1:100 molar ratio was analysed by ESI MS analysis after 10 min of mixing. The spectrum (Figure S12) shows characteristic peaks at 243.1381 and 463.2826 for [3,5-DTBQ-Na] ${ }^{+}$and [(3,5-DTBQ $)_{2}-$ $\mathrm{Na}]^{+}$, respectively. A less intense peak at $m / z=529.2846$ is assigned to the catalyst-substrate aggregate $[\mathrm{Mn}$ (hydrolysed-HL1)(3,5-DTSQH $\left.)\left(\mathrm{OH}_{2}\right)\right]^{+}\left(\mathrm{C}_{27} \mathrm{H}_{40} \mathrm{MnNO}_{6}\right.$; Calc. 529.2236). The less intense peak at 543.3 can be assigned to the species [Mn(hydrolysed-HL1)(DTBCH) $\left.\left(\mathrm{O}_{2}\right)\right]^{+}$ $\left(\mathrm{C}_{27} \mathrm{H}_{37} \mathrm{MnNO}_{7}\right.$, Calc 542.1951). The HRMS analysis of 2 in methanol (Figure S13) resulted peaks at $m / z=266.1382,367.2243$ and 583.1844 from the fragments $\left[\mathrm{H}_{3} \mathrm{~L} 3-\mathrm{H}\right]^{+}\left(\mathrm{C}_{14} \mathrm{H}_{20} \mathrm{NO}_{4}\right.$; Calcd. 266.1392), $\left[\mathrm{Mn}(\mathrm{L} 3)\left(\mathrm{OH}_{2}\right)\left(\mathrm{CH}_{3} \mathrm{OH}\right)\right]^{+} \quad\left(\mathrm{C}_{15} \mathrm{H}_{22} \mathrm{MnNO}_{6} ; \quad\right.$ Calc. 367.0828$)$ and $\left[\mathrm{Mn}_{2}\left(\mathrm{H}_{3} \mathrm{~L} 2\right)\left(\mathrm{O}_{2} \mathrm{CC}_{2} \mathrm{H}_{5}\right)\left(\mathrm{OH}_{2}\right)_{2}\right]^{+}\left(\mathrm{C}_{22} \mathrm{H}_{37} \mathrm{Mn}_{2} \mathrm{~N}_{2} \mathrm{O}_{9}\right.$; Calcd. 583.1260) present in solution. The molecular ion peak corresponding to the formula $[\mathrm{M}]^{2+}\left(\mathrm{C}_{78} \mathrm{H}_{110} \mathrm{Mn}_{6} \mathrm{~N}_{6} \mathrm{O}_{28}\right.$; Calcd. $m / z=$ 
954.1825) appears at $m / z=954.1841$. The HRMS (Figure S14) of 2 with added 3,5-DTBCH (1:100) was recorded in $\mathrm{MeOH}$ solvent after 10 min of mixing. The spectrum provided a strong base peak at $m / z=243.1349$ and a medium intense peak at 463.2826, for quinone bearing fragments $[3,5-\mathrm{DTBQ}-\mathrm{Na}]^{+}$and $\left[(3,5-\mathrm{DTBQ})_{2}-\mathrm{Na}\right]^{+}$, respectively. The catalyst-substrate aggregate was detected at $m / z=353.2260$ for $[\mathrm{Mn}(\mathrm{HL} 3)(3,5-\mathrm{DTBQ})-\mathrm{Na}]^{+}\left(\mathrm{C}_{28} \mathrm{H}_{37} \mathrm{MnNNaO}_{6}\right.$; Calcd. 561.1899). Another small peak at 705.4436 agrees to the fragment $\left[\mathrm{Mn}\left(\mathrm{H}_{2} \mathrm{~L} 3\right)(\mathrm{DTBCH})\left(\mathrm{O}_{2}\right)\left(\mathrm{ClO}_{4}\right)\left(\mathrm{CH}_{3} \mathrm{OH}\right)\right] \mathrm{H}^{+}\left(\mathrm{C}_{29} \mathrm{H}_{44} \mathrm{ClMnNO}_{13}\right.$, Calc. 704.1882).

Fragments in MeCN. The HRMS spectra for 1 and 2 were also recorded in MeCN solution. In case of 1 (Figure S15), the peaks at $m / z=307.2017$ and 329.0686 are assigned to the ligand associated with molecular formulas $\left[\mathrm{H}_{3} \mathrm{~L} 1-\mathrm{H}\right]^{+}\left(\mathrm{C}_{17} \mathrm{H}_{27} \mathrm{~N}_{2} \mathrm{O}_{3}\right.$; Calcd. 307.2022) and $\left[\mathrm{H}_{3} \mathrm{~L} 1-\mathrm{Na}\right]^{+}$ $\left(\mathrm{C}_{17} \mathrm{H}_{26} \mathrm{~N}_{2} \mathrm{NaO}_{3}\right.$; Calcd. 329.1841). The presence of protonated hydrolysed ligand [hydrolysed$\left.\mathrm{H}_{2} \mathrm{~L} 1-\mathrm{H}\right]^{+}\left(\mathrm{C}_{13} \mathrm{H}_{18} \mathrm{NO}_{3}\right)$ was confirmed by the peak at $m / z=236.1301$ (Calcd. 236.1287). The mononuclear cationic molecular ion fragment $\left[\mathrm{Mn} \text { (hydrolysed-HL1) }\left(\mathrm{O}_{2} \mathrm{CCH}_{3}\right)\left(\mathrm{OH}_{2}\right)-\mathrm{K}\right]^{+}$ $\left(\mathrm{C}_{15} \mathrm{H}_{21} \mathrm{KMnNO}_{6}\right.$ ) gave a peak at $\mathrm{m} / \mathrm{z}=405.1221$ (Calc. 405.0386). The 1:100 mixture of 1 and 3,5-DTBC (after 10 min of mixing) resulted two characteristic peaks at $\mathrm{m} / \mathrm{z}=243.1348$ and 463.2815, respectively for $[\mathrm{DTBQ}-\mathrm{Na}]^{+}$and $\left[(\mathrm{DTBQ})_{2}-\mathrm{Na}\right]^{+}$(Figure S16). The characteristic peak for complex-substrate aggregate $\left[\mathrm{Mn}\left(\mathrm{H}_{2} \mathrm{~L} 1\right)(3,5-\mathrm{DTBC})-\mathrm{Na}\right]^{+} \quad\left(\mathrm{C}_{31} \mathrm{H}_{45} \mathrm{MnN}_{2} \mathrm{O}_{5} \mathrm{Na}\right)$ appeared as a small signal at $m / z=603.2462$ (Calcd. 603.2607). The peak at 543.3 corresponding to the $\mathrm{O}_{2}$ bound fragment $\left[\mathrm{Mn}^{\mathrm{III}}\left(\text { hydrolysed-HL1) }(\mathrm{DTBCH})\left(\mathrm{O}_{2}\right)\right]^{+}\right.$in $\mathrm{MeCN}$ medium has also been detected with certainty. Compound 2 in $\mathrm{MeCN}$ solution recorded a base peak at $\mathrm{m} / \mathrm{z}=$ 367.2250 for the protonated ligand species $\left[\mathrm{H}_{5} \mathrm{~L} 2-\mathrm{H}\right]^{+}\left(\mathrm{C}_{19} \mathrm{H}_{31} \mathrm{~N}_{2} \mathrm{O}_{5}\right.$; Calcd. 367.2233) (Figure $\mathrm{S} 17)$. Other peaks at $\mathrm{m} / \mathrm{z}=337.2132,419.1398$ and 806.1134 were assigned to the cationic molecular fragments $\left[\mathrm{Mn}\left(\mathrm{H}_{2} \mathrm{~L} 3\right)\left(\mathrm{OH}_{2}\right)\right]^{+} \quad\left(\mathrm{C}_{14} \mathrm{H}_{20} \mathrm{MnNO}_{5}\right.$; Calcd. 337.0722), $\left[\mathrm{Mn}\left(\mathrm{H}_{3} \mathrm{~L} 2\right)\right]^{+}$ $\left(\mathrm{C}_{19} \mathrm{H}_{28} \mathrm{MnN}_{2} \mathrm{O}_{5} ; \quad\right.$ Calcd. 419.1379) and $\quad\left[\mathrm{Mn}_{3}(\mathrm{~L} 2)\left(\mathrm{O}_{2} \mathrm{CC}_{2} \mathrm{H}_{5}\right)_{3}\left(\mathrm{NCCH}_{3}\right)\left(\mathrm{OH}_{2}\right)\right]^{+}$ $\left(\mathrm{C}_{30} \mathrm{H}_{45} \mathrm{Mn}_{3} \mathrm{~N}_{3} \mathrm{O}_{12}\right.$; Calcd. 804.1145).

Thus, the ESI-MS spectra allow us to conclude that the complex-substrate intermediates are formed during oxidation reactions of $\mathrm{DTBCH}_{2}$ to 3,5-DTBQ by $\mathrm{O}_{2}$ of air. The analysis also established that the ligand/hydrolysed-ligand bound mononuclear fragments are the catalytically active species in both the cases. The catalytic activity was not observed in case of $\mathbf{2}$ in $\mathrm{MeCN}$ due non-availability of the active mononuclear fragment in MeCN medium. 
Probable Mechanism. Studied reaction kinetics showed that both the two complexes were reactive for simulating the catechol oxidase activity and the rate saturation kinetics indicate that the oxidation reaction proceeds smoothly through a stable complex-substrate intermediate as observed for some mononuclear manganese(II) complexes. ${ }^{67}$ Solution phase EPR spectral measurements were performed to comment on the catalytic pathways for the oxidation reactions. In $\mathrm{MeOH}$, separate mixtures of $\mathbf{1}$ and $\mathbf{2}$ with DTBC (1:100) in methanol solution were examined following the recorded EPR spectra. Complex 1, containing one $\mathrm{Mn}^{\mathrm{II}}$, generated hyperfine sextet (six-line) EPR spectra with g values 2.14, 2.09, 2.03, 1.97, 1.92 and 1.87 and $A_{a v}$ value of 93.2 G. The six hyperfine lines are due to the interaction of the electron spin with the nuclear spin $\left({ }^{55} \mathrm{Mn}, \mathrm{I}=5 / 2\right) \cdot{ }^{73}$ Interestingly, upon addition of 100 equivalents of the substrate to the solutions of $\mathbf{1}$, the intensity of six-line hyperfine splitting pattern in the spectrum is increased which suggests that the concentration of manganese(II) species is increased in several fold after addition of the substrate (Figure 14). The spectrum also allowed us to detect the presence of an organic radical at $\mathrm{g}=2.009$ following the conversion of DTBC to DTBQ in radical pathway. Expanded scan in the region showed further splitting into two lines $\left(a_{\mathrm{av}}, 3.09 \mathrm{G}\right)$. Similarly, complex 2, which is silent in present working mode of EPR (perpendicular mode), also indicated the conversion of DTBC to DTBQ from sextet EPR lines originating from the reaction generated $\mathrm{Mn}^{\mathrm{II}}$ along with signal for the organic radical. From the combined ESI-MS and EPR spectra analysis a plausible mechanistic pathway is proposed in Scheme S2.

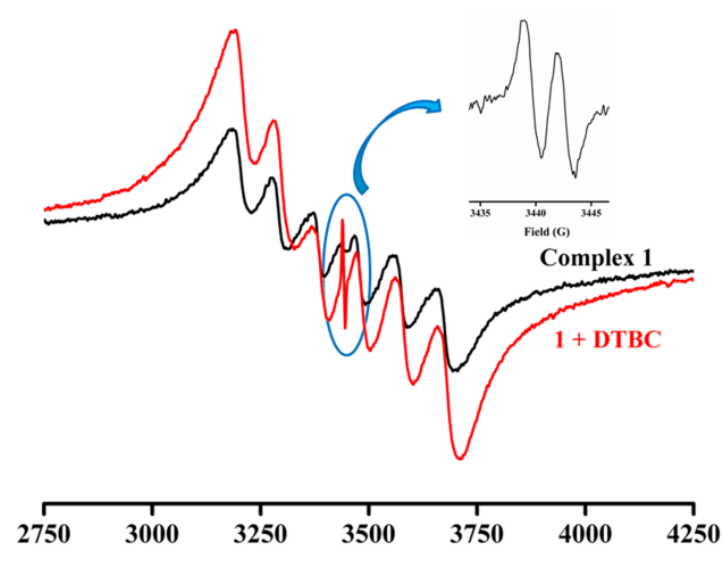

Field (G)
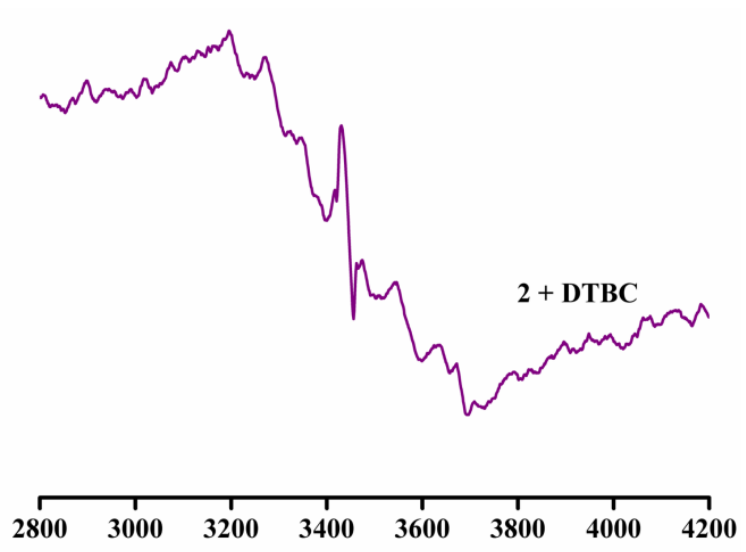

Field (G)

Figure 14. EPR spectra of $\mathbf{1}$ (black) and 1:100 mixtures (red and violet) of 1 and 2 with 3,5 DTBC in MeOH at room temperature. 
Conclusion. Trinuclear and hexanuclear manganese complexes have been presented from unusual binding of ligands having dangling and hydrolysed arms. Two closely related binucleating ligands have been used for mixed-valent linear $\mathrm{Mn}^{\mathrm{III}}{ }_{2} \mathrm{Mn}^{\mathrm{II}}$ and fused diadamantane type $\mathrm{Mn}_{6}{ }_{6}$ coordination aggregates in $\mathbf{1}$ and $\mathbf{2}$. The study also examined the relative stability of the imine functions not utilized for coordination to manganese ions. Very unusual binding modes and coordination from terminal alcohol ends of the ligands were observed during the growth of such multimetallic assemblies. In $\mathrm{MeOH}$ reaction medium the externally added carboxylates and in situ generated hydroxido groups were involved in competitive metal ion binding for the growth of aggregates. The work also establishes the coordination flexibility and bridging preference of the used ligands. The deprotonated phenol part and protonated as well as deprotonated alcohol ends were utilized for the growth of new manganese aggregates of varying nuclearity and contrasting molecular topology. The intramolecular exchange interactions in $\mathbf{1}$ and $\mathbf{2}$ are antiferromagnetic in nature. For 1, the magnetic susceptibility and magnetisation data were fitted simultaneously using one coupling constant and the single-ion axial magnetic anisotropy on the two $\mathrm{Mn}$ (III) centers. The $a c$ data showed that $\mathbf{1}$ displayed a field-induced slow magnetic relaxation at $2 \mathrm{~K}$. For 2 , in the fit of $\chi_{\mathrm{M}} T v s$. $T$ four different coupling constants were justified in the accordance with the different $\mathrm{Mn} \cdots \mathrm{Mn}$ interactions and found to be in good agreement with DFT calculations. Both the complexes exhibit catecholase-like activity towards 3,5- $\mathrm{DTBCH}_{2}$ as the model substrate with comparable catalytic efficiency with a pronounced solvent effect in case of the former. Kinetic studies on the solvent dependent oxidation reaction of 3,5-di-tertbutylcatechol by $\mathrm{O}_{2}$ in solution establish both the trinuclear and hexanuclear complexes as efficient catalysts in $\mathrm{MeOH}$. In MeCN medium, complex 2 is inactive. ESI-MS (positive) proofs clearly advocate the presence of mononuclear manganese complex-catechol collections and bidentate coordination mode of catechol unit undergoing oxidation.

\section{Associated Content}

\section{$\dagger$ Electronic supplementary information}

X-ray crystallographic data in CIF format, Schemes S1-S2, Figures S1-S17, Tables S1-S7. CCDC 1517620 and 1517621 contain the supplementary crystallographic data in CIF format for complexes 1-3. 
Acknowledgments. K.C. is thankful to the Council of Scientific and Industrial Research, New Delhi for the financial support. K.C. is thankful to Dr. Debamalya Banerjee for his kind help in collecting EPR data. We are also thankful to DST, New Delhi, for providing the Single Crystal X-ray Diffractometer facility to the Department of Chemistry, IIT Kharagpur under its FIST program. A.F. thanks the DGICYT of Spain (project CTQ2014-57393-C2-1-P, FEDER funds). We thank the CTI (UIB) for computational facilities. We are thankful to the reviewers for their valuable suggestions to improve the quality of the manuscript.

\section{Author Information}

Corresponding Author

*E-mail: dray@ chem.iitkgp.ernet.in. Tel: (+91) 3222-283324. Fax: (+91) 3222-82252.

Notes

The authors declare no competing financial interest 


\section{References}

(1) Hoffman, B. M.; Dean, D. R.; Seefeldt, L. C. Climbing nitrogenase: toward a mechanism of enzymatic nitrogen fixation. Acc. Chem. Res. 2009, 42, 609-619.

(2) Zouni, A.; Witt, H. T.; Kern, J.; Fromme, P.; Krauss, N.; Saenger, W.; Orth, P. Crystal structure of photosystem II from Synechococcus elongatus at $3.8 \AA$ resolution. Nature 2001, 409, 739-743.

(3) Kamiya, N.; Shen, J. R. Crystal structure of oxygen-evolving photosystem II from Thermosynechococcus vulcanus at 3.7-^̊ resolution. Proc. Natl. Acad. Sci. U. S. A. 2003, 100, 98-103.

(4) Ferreira, K. N.; Iverson, T. M.; Maghlaoui, K.; Barber, J.; Iwata, S. Architecture of the photosynthetic oxygen-evolving center. Science 2004, 303, 1831-1838.

(5) Biesiadka, J.; Loll, B.; Kern, J.; Irrgang, K. D.; Zouni, A. Crystal structure of cyanobacterial photosystem II at $3.2 \AA$ resolution: a closer look at the Mn-cluster. Phys. Chem. Chem. Phys. 2004, 6, 4733-4736.

(6) Carrell, T.; Tyryshkin, A.; Dismukes, G. An evaluation of structural models for the photosynthetic water-oxidizing complex derived from spectroscopic and X-ray diffraction signatures. J. Biol. Inorg. Chem. 2002, 7, 2-22.

(7) Cinco, R. M.; Rompel, A.; Visser, H.; Aromí, G.; Christou, G.; Sauer, K.; Klein, M. P.; Yachandra, V. K. Comparison of the manganese cluster in oxygen-evolving photosystem II with distorted cubane manganese compounds through X-ray absorption spectroscopy. Inorg. Chem. 1999, 38, 5988-5998.

(8) Yachandra, V. K.; Sauer, K.; Klein, M. P. Manganese cluster in photosynthesis: where plants oxidize water to dioxygen. Chem. Rev. 1996, 96, 2927-2950.

(9) Bagai, R.; Abboud, K. A.; Christou, G. Ligand-induced distortion of a tetranuclear manganese butterfly complex. Dalton Trans. 2006, 3306-3312.

(10) Hamilton, C. R.; Gau, M. R.; Baglia, R. A.; McWilliams, S. F.; Zdilla, M. J. Mechanistic Elucidation of the stepwise formation of a tetranuclear manganese pinned butterfly cluster via $\mathrm{N}-\mathrm{N}$ bond cleavage, hydrogen atom transfer, and cluster rearrangement. J. Am. Chem. Soc. 2014, 136, 17974-17986. 
(11) Yang, H.; Cao, F.; Li, D.; Zeng, S.; Song, Y.; Dou, J. Solvent dependent reactivities of di-, tetra-and hexanuclear manganese complexes: syntheses, structures and magnetic properties. Dalton Trans. 2015, 44, 6620-6629.

(12) Elshaarawy, R. F. M.; Lan, Y.; Janiak, C. Oligonuclear homo- and mixed-valence manganese complexes based on thiophene- or aryl-carboxylate ligation: Synthesis, characterization and magnetic studies. Inorg. Chimi. Acta 2013, 401, 85-94.

(13) Ledesma, G. N.; Anxolabéhère-Mallart, E.; Rivière, E.; Mallet-Ladeira, S.; Hureau, C.; Signorella, S. R. Trinuclear manganese complexes of unsymmetrical polypodal diamino $\mathrm{N}_{3} \mathrm{O}_{3}$ ligands with an unusual $\left[\mathrm{Mn}_{3}(\mu-\mathrm{OR})_{4}\right]^{5+}$ triangular core: synthesis, characterization, and catalase activity. Inorg. Chem. 2014, 53, 2545-2553.

(14) Ghosh, A. K.; Shatruk, M.; Bertolasi, V.; Pramanik, K.; Ray, D. Self-assembled tetraand pentanuclear nickel(II) aggregates from phenoxido-based ligand-bound $\left\{\mathrm{Ni}_{2}\right\}$ fragments: carboxylate bridge controlled structures. Inorg. Chem. 2013, 52, 1389413903.

(15) Adhikary, J.; Chakraborty, A.; Dasgupta, S.; Chattopadhyay, S. K.; Kruszynski, R.; Trzesowska-Kruszynska, A.; Stepanović, S.; Gruden-Pavlović, M.; Swart, M.; Das, D. Unique mononuclear $\mathrm{Mn}^{\mathrm{II}}$ complexes of an end-off compartmental Schiff base ligand: experimental and theoretical studies on their bio-relevant catalytic promiscuity. Dalton Trans. 2016, 45, 12409-12422.

(16) Chakraborty, P.; Majumder, I.; Banu, K. S.; Ghosh, B.; Kara, H.; Zangrando, E.; Das, D. $\mathrm{Mn}(\mathrm{II})$ complexes of different nuclearity: synthesis, characterization and catecholase-like activity. Dalton Trans. 2016, 45, 742-752.

(17) Milios, C. J.; Manoli, M.; Rajaraman, G.; Mishra, A.; Budd, L. E.; White, F.; Parsons, S.; Wernsdorfer, W.; Christou, G.; Brechin, E. K. A family of [ $\left.\mathrm{Mn}_{6}\right]$ complexes featuring tripodal ligands. Inorg. Chem. 2006, 45, 6782-6793.

(18) Sawada, Y.; Kosaka, W.; Hayashi, Y.; Miyasaka, H. Coulombic aggregations of Mn ${ }^{\mathrm{III}}$ salen-type complexes and Keggin-type polyoxometalates: isolation of $\mathrm{Mn}_{2}$ singlemolecule magnets. Inorg. Chem. 2012, 51, 4824-4832.

(19) Martínez-Lillo, J.; Tomsa, A.-R.; Li, Y.; Chamoreau, L.-M.; Cremades, E.; Ruiz, E.; Barra, A.-L.; Proust, A.; Verdaguer, M.; Gouzerh, P. Synthesis, crystal structure and 
magnetism of new salicylamidoxime-based hexanuclear manganese (III) single-molecule magnets. Dalton Trans. 2012, 41, 13668-13681.

(20) Zhang, L.; Onet, C. I.; Clérac, R.; Rouzières, M.; Marzec, B.; Boese, M.; Venkatesan, M.; Schmitt, W. A facile "bottom-up" approach to prepare free-standing nano-films based on manganese coordination clusters. Chem. Commun. 2013, 49, 7400-7402.

(21) Wang, P.; Yap, G. P. A.; Riordan, C. G. Five-coordinate $\mathrm{M}^{\mathrm{II}}$-semiquinonate $(\mathrm{M}=\mathrm{Fe}$, $\mathrm{Mn}, \mathrm{Co})$ complexes: reactivity models of the catechol dioxygenases. Chem. Commun. 2014, 50, 5871-5873.

(22) Dey, S. K.; Mukherjee, A. The synthesis, characterization and catecholase activity of dinuclear cobalt (II/III) complexes of an O-donor rich Schiff base ligand. New J. Chem. 2014, 38, 4985-4995.

(23) Biswas, A.; Das, L. K.; Drew, M. G. B.; Aromí, G.; Gamez, P.; Ghosh, A. Synthesis, crystal structures, magnetic properties and catecholase activity of double phenoxidobridged penta-coordinated dinuclear nickel (II) complexes derived from reduced Schiffbase ligands: mechanistic inference of catecholase activity. Inorg. Chem. 2012, 51, 79938001.

(24) Pait, M.; Bauza, A.; Frontera, A.; Colacio, E.; Ray, D. A new family of $\mathrm{Ni}_{4}$ and $\mathrm{Ni}_{6}$ aggregates from the self-assembly of $\left[\mathrm{Ni}_{2}\right]$ building units: role of carboxylate and carbonate bridges. Inorg. Chem. 2015, 54, 4709-4723.

(25) Dhara, K.; Saha, U. C.; Dan, A.; Sarkar, S.; Manasserod, M.; Chattopadhyay, P. A new water-soluble copper (II) complex as a selective fluorescent sensor for azide ion. Chem. Commun. 2010, 46, 1754-1756.

(26) Gagne, R. R.; Spiro, C. L.; Smith, T. J.; Hamann, C. A.; Thies, W. R.; Shiemke, A. K. The synthesis, redox properties, and ligand binding of heterobinuclear transition-metal macrocyclic ligand complexes. Measurement of an apparent delocalization energy in a mixed-valent copper(I) copper(II) complex. J. Am. Chem. Soc. 1981, 103, 4073-4081.

(27) Saint, Smart and XPREP, Siemens Analytical X-ray Instruments Inc., Madison, WI, 1995.

(28) Sheldrick, G. M. SHELXS-97, Universityof Göttingen, Göttingen, Germany, 1997. 
(29) Sheldrick, G. M. SHELXL 97, Program for Crystal Structure Refinement, University of Göttingen, Göttingen, Germany, 1997.

(30) Farrugia, L. WinGX System, v. 1.80.05, University of Glasgow, UK.

(31) DIAMOND, Visual Crystal Structure Information System, version 3.1, Crystal Impact, Bonn, Germany, 2004.

(32) Farrugia, L. J.: POV-Ray - 3.5. Australia: Glasgow University; 2003.

(33) Noodleman, L. J.; Valence bond description of antiferromagnetic coupling in transition metal dimers. J. Chem. Phys. 1981, 74, 5737-5743.

(34) Noodleman, L.; Davidson, E. R. Ligand spin polarization and antiferromagnetic coupling in transition metal dimers. Chem. Phys. 1986, 109, 131-143.

(35) Noodleman, L.; Peng, C. Y.; Case, D. A.; Mouesca, J. M. Orbital interactions, electron delocalization and spin coupling in iron-sulfur clusters. Coord. Chem. Rev. 1995, 144, 199-244.

(36) Gaussian 09, Revision D.01; Frisch, M. J.; Trucks, G. W.; Schlegel, H. B.; Scuseria, G. E.; Robb, M. A.; Cheeseman, J. R.; Scalmani, G.; Barone, V.; Mennucci, B.; Petersson, G. A.; Nakatsuji, H.; Caricato, M.; Li, X.; Hratchian, H. P.; Izmaylov, A. F.; Bloino, J.; Zheng, G.; Sonnenberg, J. L.; Hada, M.; Ehara, M.; Toyota, K.; Fukuda, R.; Hasegawa, J.; Ishida, M.; Nakajima, T.; Honda, Y.; Kitao, O.; Nakai, H.; Vreven, T.; Montgomery, J. A.; Peralta, Jr., J. E.; Ogliaro, F.; Bearpark, M.; Heyd, J. J.; Brothers, E.; Kudin, K. N.; Staroverov, V. N.; Kobayashi, R.; Normand, J.; Raghavachari, K.; Rendell, A.; Burant, J. C.; Iyengar, S. S.; Tomasi, J.; Cossi, M.; Rega, N.; Millam, J. M.; Klene, M.; Knox, J. E.; Cross, J. B.; Bakken, V.; Adamo, C.; Jaramillo, J.; Gomperts, R.; Stratmann, R. E.; Yazyev, O.; Austin, A. J.; Cammi, R.; Pomelli, C.; Ochterski, J. W.; Martin, R. L.; Morokuma, K.; Zakrzewski, V. G.; Voth, G. A.; Salvador, P.; Dannenberg, J. J.; Dapprich, S.; Daniels, A. D.; Farkas, Ö.; Foresman, J. B.; Ortiz, J. V.; Cioslowski, J.; Fox, D. J. Gaussian, Inc., Wallingford CT, 2009.

(37) Costa, R.; Valero, R.; Mañeru, D. R.; Moreira, I. de P. R.; Illas, F. Spin adapted versus broken symmetry approaches in the description of magnetic coupling in heterodinuclear complexes. J. Chem. Theory Comput. 2015, 11, 1006-1019. 
(38) Mañeru, D. R.; Costa, R.; Márquez, M. G.; Moreira, I. de P. R.; Illas, F. Handling magnetic coupling in trinuclear Cu (II) complexes. J. Chem. Theory Comput. 2015, 11, $3650-3660$.

(39) Ruiz, E.; Rodríguez-Fortea, A.; Cano, J.; Alvarez, S.; Alemany, P. About the calculation of exchange coupling constants in polynuclear transition metal complexes. $J$. Comput. Chem. 2003, 24, 982-989.

(40) Ruiz, E.; Alvarez, S.; Cano, J.; Polo, V. About the calculation of exchange coupling constants using density-functional theory: The role of the self-interaction error. J. Chem. Phys. 2005, 123, 164110-164117.

(41) Mandal, D.; Bertolasi, V.; Ribas-Ariño, J.; Aromí, G.; Ray, D. Self-Assembly of an Azido-Bridged $\left[\mathrm{Ni}_{6}{ }_{6}\right]$ Cluster Featuring Four Fused Defective Cubanes. Inorg. Chem. 2008, 47, 3465-3467.

(42) Liu, W.; Thorp, H. H. Bond valence sum analysis of metal-ligand bond lengths in metalloenzymes and model complexes. 2. Refined distances and other enzymes. Inorg. Chem. 1993, 32, 4102-4105.

(43) Brown, I. D. Recent developments in the methods and applications of the bond valence model. Chem. Rev. 2009, 109, 6858-6919.

(44) Tandon, S. S.; Bunge, S. D.; Sanchiz, J.; Thompson, L. K. Structures and magnetic properties of an antiferromagnetically coupled polymeric copper(II) complex and ferromagnetically coupled hexanuclear nickel(II) clusters. Inorg. Chem. 2012, 51, 32703282.

(45) Ma, Y. S.; Yao, H. C.; Hua, W. J.; Li, S. H.; Li, Y. Z.; Zheng, L. M. Tetranuclear manganese (III) clusters containing both carboxylate and phosphonate bridging ligands. Inorg. Chimi. Acta 2007, 360, 1645-1650.

(46) Libby, E.; McCusker, J. K.; Schmitt, E. A.; Folting, K.; Hendrickson, D. N.; Christou, G. Preparation and properties of models for the photosynthetic water oxidation center: spin frustration in the manganese $\left[\mathrm{Mn}_{4} \mathrm{O}_{2}\left(\mathrm{O}_{2} \mathrm{CR}\right)_{7}(\text { pic })_{2}\right]$-anion. Inorg. Chem. 1991, 30, 3486-3495.

(47) Aromí, G.; Bhaduri, S.; Artús, P.; Folting, K.; Christou, G. Bridging nitrate groups in $\left[\mathrm{Mn}_{4} \mathrm{O}_{3}\left(\mathrm{NO}_{3}\right)\left(\mathrm{O}_{2} \mathrm{CMe}\right)_{3}\left(\mathrm{R}_{2} \mathrm{dbm}\right)_{3}\right](\mathrm{R}=\mathrm{H}, \mathrm{Et})$ and $\left[\mathrm{Mn}_{4} \mathrm{O}_{2}\left(\mathrm{NO}_{3}\right)\left(\mathrm{O}_{2} \mathrm{CEt}\right)_{6}(\mathrm{bpy})_{2}\right]\left(\mathrm{ClO}_{4}\right)$ : 
acidolysis routes to tetranuclear manganese carboxylate complexes. Inorg. Chem. 2002, $41,805-817$.

(48) Escuer, A.; Mayans, J.; Font-Bardia, M. Copper(II) cubanes with a $\{\mathrm{Cu} 4 \mathrm{O}\}$ core and well defined $S=1$ ground state. Dalton Trans. 2016, 45, 1604-1613.

(49) Pait, M.; Colacio, E.; Ray, D. Novel anion-tunable structural diversity and new topologies in $\mathrm{Cu}^{\mathrm{II}}$ complexes of a Schiff base. Polyhedron 2015, 88, 90-100.

(50) Milios, C. J.; Inglis, R.; Vinslava, A.; Bagai, R.; Wernsdorfer, W.; Parsons, S.; Perlepes, S. P.; Christou, G.; Brechin, E. K. J. Am. Chem. Soc. 2007, 129, 12505-12511.

(51) Taguchi, T.; Daniels, M. R.; Abboud, K. A.; Christou, G. Mn4, Mn6 and $\mathrm{Mn}_{11}$ clusters from the use of bulky diphenyl(pyridine-2-yl)methanol. Inorg. Chem. 2009, 48, 93259335.

(52) Stamatatos, T. C.; Luisi, B. S.; Moulton, B.; Christou, G. Employment of 2,6diacetylpyridine dioxime as a new route to high nuclearity metal clusters: $\mathrm{Mn}_{6}$ and $\mathrm{Mn}_{8}$ complexes. Inorg. Chem. 2008, 47, 1134-1144.

(53) Chilton, N. F.; Anderson, R. P.; Turner, L. D.; Soncini, A.; Murray, K. S. PHI: A powerful new program for the analysis of anisotropic monomeric and exchange-coupled polynuclear d-and f-block complexes. J. Comput. Chem. 2013, 34, 1164-1174.

(54) Pait, M.; Shatruk, M.; Ray D. Anion coordination selective $\left[\mathrm{Mn}_{3}\right]$ and $\left[\mathrm{Mn}_{4}\right]$ assemblies: Synthesis, structural diversity, magnetic properties and catechol oxidase activity. Dalton Trans. 2015, 44, 11741-11754.

(55) Kessissoglou, D. P.; Kirk, M. L.; Lah, M. S.; Li, X.; Raptopoulou, C.; Hatfield, W. E.; Pecoraro, V. L. Structural and magnetic characterization of trinuclear, mixed-valence manganese acetates. Inorg. Chem. 1992, 31, 5424-5432.

(56) Boča, R. A Handbook of Magnetochemical Formulae, Elsevier Inc., 2012.

(57) Tziotzi, T. G.; Philippidis, A.; Raptopoulou, C. P.; Psycharis, V.; Milios, C. J. Employment of a naphthalene-based tetraol ligand in Mn chemistry: Mononuclear and linear trinuclear clusters. Polyhedron 2013, 64, 52-58.

(58) Duboc, C. Determination and prediction of the magnetic anisotropy of Mn ions. Chem. Soc. Rev. 2016, 45, 5834-5847. 
(59) Wemple, M. W.; Tsai, H.-L.; Wang, S.; Claude, J. P.; Streib, W. E.; Huffman, J. C.; Hendrickson, D. N.; Christou, G. Tetranuclear and octanuclear manganese carboxylate clusters: preparation and reactivity of $\left.\left(\mathrm{NBu}_{4}\right)^{\mathrm{n}}\right)\left[\mathrm{Mn}_{4} \mathrm{O}_{2}\left(\mathrm{O}_{2} \mathrm{CPh}\right)_{9}\left(\mathrm{H}_{2} \mathrm{O}\right)\right]$ and synthesis of $\left(\mathrm{NBu}_{4}\right)_{2}\left[\mathrm{Mn}_{8} \mathrm{O}_{4}\left(\mathrm{O}_{2} \mathrm{CPh}\right)_{12}\left(\mathrm{Et}_{2} \mathrm{mal}\right)_{2}\left(\mathrm{H}_{2} \mathrm{O}\right)_{2}\right]$ with a "Linked-Butterfly" structure. Inorg. Chem. 1996, 35, 6437-6449.

(60) Kanady, J. S.; Tran, R.; Stull, J. A.; Lu, L.; Stich, T. A.; Day, M. W.; Yano, J.; Britt, R. D.; Agapie, T. Role of oxido incorporation and ligand lability in expanding redox accessibility of structurally related $\mathrm{Mn}_{4}$ clusters. Chem. Sci. 2013, 4, 3986-3996.

(61) Aromí, G.; Bhaduri, S.; Artús, P.; Huffman, J. C.; Hendrickson, D. N.; Christou, G. A tetranuclear manganese carboxylate cluster with bis(2-pyridyl)amine ligation: $\left[\mathrm{Mn}_{4} \mathrm{O}_{2}\left(\mathrm{O}_{2} \mathrm{CEt}\right)_{7}(\mathrm{bpya})_{2}\right]\left(\mathrm{ClO}_{4}\right)$. Polyhedron 2002, 21, 1779-1786.

(62) Albela, B.; El Fallah, M. S.; Ribas, J. Two new mixed-valence manganese complexes of formula $\left[\mathrm{Mn}_{4} \mathrm{O}_{2}(\mathrm{X} \text {-benzoato })_{7}(\mathrm{bpy})_{2}\right](\mathrm{X}=2-\mathrm{Cl}, 2-\mathrm{Br})$ and the crystal structure of the 2$\mathrm{Cl}$ complex: Ground-state spin variability in the $\left[\mathrm{Mn}_{4} \mathrm{O}_{2}\right]^{7+}$ complexes. Inorg. Chem. 2001, 40, 1037-1044.

(63) Wang, S.; Wemple, M. S.; Yoo, J.; Folting, K.; Huffman, J. C.; Hagen, K. S.; Hendrickson, D. N.; Christou, G. Tetranuclear manganese carboxylate complexes with a trigonal pyramidal metal topology via controlled potential electrolysis. Inorg. Chem. 2000, 39, 1501-1513.

(64) Christmas, C.; Vincent, J. B.; Chang, H. R.; Huffman, J. C.; Christou, G.; Hendrickson, D. N. Nonanuclear oxide-bridged manganese complex. Preparation, structure, and magnetic properties of $\left[\mathrm{Mn}_{9} \mathrm{O}_{4}\left(\mathrm{O}_{2} \mathrm{CPh}\right)_{8}(\mathrm{sal})_{4}(\mathrm{salH})_{2}(\mathrm{pyr})_{4}\right]\left(\mathrm{salH}_{2}=\right.$ salicylic acid; $\mathrm{pyr}=$ pyridine) J. Am. Chem. Soc. 1988, 110, 823-830.

(65) Yang, P.-P.; Song, X.-Y.; Liu, R.-N.; Li, L.-C.; Liao, D.-Z. Syntheses, crystal structures and magnetic properties of a novel family of penta-manganese complexes derived from an assembly system containing polydentate hydroxy-rich Schiff-base ligands. Dalton Trans. 2010, 39, 6285-6294.

(66) Shanmugam, M.; Shanmugam, M.; Chastanet, G.; Sessoli, R.; Mallah, T.; Wernsdorfer, W.; Winpenny, R. E. P. Minor changes in phosphonate ligands lead to new hexa-and dodeca-nuclear Mn clusters. J. Mater. Chem. 2006, 16, 2576-2578. 
(67) Banu, K. S., Chattopadhyay, T.; Banerjee, A.; Mukherjee, M.; Bhattacharya, S.; Patra, G. K.; Zangrando, E.; Das, D. Mono-and dinuclear manganese(III) complexes showing efficient catechol oxidase activity: syntheses, characterization and spectroscopic studies. Dalton Trans. 2009, 40, 8755-8764.

(68) Majumder, A.; Goswami, S.; Batten, S. R.; Fallah, M. S. E.; Ribas, J.; Mitra, S. Catalytic oxidation of 3,5-di-tert-butylcatechol by a manganese(III) 18-azametallacrown6 compound: Synthesis, crystal structure, fluorescence, magnetic and kinetic investigation. Inorg. Chimi. Acta 2006, 359, 2375-2382.

(69) Hitomi, Y.; Ando, A.; Matsui, H.; Ito, T.; Tanaka, T.; Ogo, S.; Funabiki, T. Aerobic catechol oxidation catalyzed by a bis( $\mu$-oxo)dimanganese(III,III) complex via a manganese(II)-semiquinonate complex. Inorg. Chem. 2005, 44, 3473-3478.

(70) Triller, M. U.; Pursche, D.; Hsieh, W. Y.; Pecoraro, V. L.; Rompel, A.; Krebs, B. Catalytic oxidation of 3,5-di-tert-butylcatechol by a series of mononuclear manganese complexes: synthesis, structure, and kinetic investigation. Inorg. Chem. 2003, 42, 62746283.

(71) Jana, A.; Aliaga-Alcalde, N.; Ruiz, E.; Mohanta, S. Structures, magnetochemistry, spectroscopy, theoretical study, and catechol oxidase activity of dinuclear and dimer-ofdinuclear mixed-valence $\mathrm{Mn}^{\mathrm{III}} \mathrm{Mn}^{\mathrm{II}}$ complexes derived from a macrocyclic ligand. Inorg. Chem. 2013, 52, 7732-7746.

(72) Kar, P.; Ida, Y.; Kanetomo, T.; Drew, M. G. B.; Ishida, T.; Ghosh, A. Synthesis of mixed-valence hexanuclear $\mathrm{Mn}(\mathrm{II} / \mathrm{III})$ clusters from its $\mathrm{Mn}(\mathrm{II})$ precursor: variations of catecholase-like activity and magnetic coupling. Dalton Trans. 2015, 44, 9795-9804.

(73) Garribba, E.; Micera, G. Determination of the hyperfine coupling constant and zerofield splitting in the ESR spectrum of $\mathrm{Mn}^{2+}$ in calcite. Magn. Reson. Chem. 2006, 44, 1119. 


\section{For Table of Contents Only}

Synopsis. Ligands $\mathrm{H}_{3} \mathrm{~L} 1$ and $\mathrm{H}_{5} \mathrm{~L} 2$ with potential donor atom bearing flexible side arms lead to $\left[\mathrm{Mn}_{3}\right]$ and $\left[\mathrm{Mn}_{6}\right]$ coordination aggregates of fascinating and uncommon molecular structures. The nature of the phenol based ligands and other smaller ancillary bridges influence the structural, magnetic and functional properties.

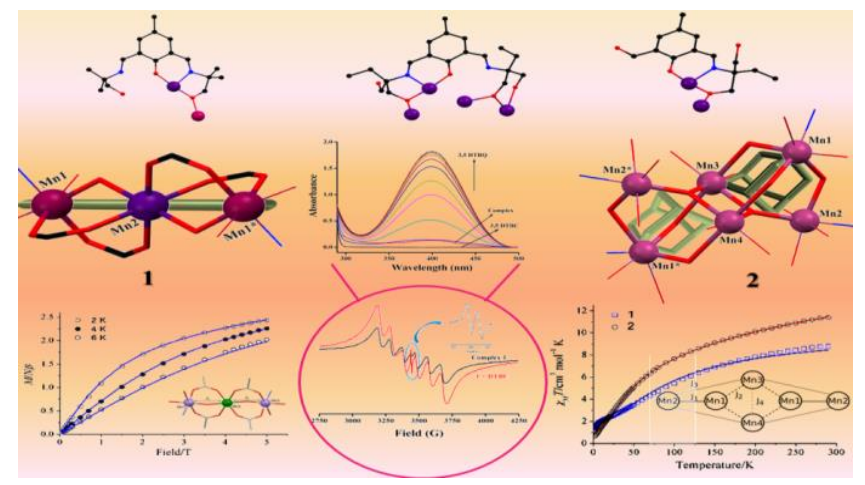

